\title{
A Serine Proteinase Involved in Contact Mediated Repulsion of Retinal Growth Cones by DRG Neurites
}

\author{
Janet L. Baird and Jonathan A. Raper \\ Department of Neurosciences, University of Pennsylvania School of Medicine, Philadelphia, Pennsylvania 19104
}

\begin{abstract}
Cultured retinal ganglion cell growth cones avoid neurites extending from PNS explants. Here we characterize a growth cone collapsing activity in detergent extracts of newborn calf adrenal plasma membranes that has characteristics expected for an avoidance cue on peripheral neurites. This adrenal derived activity induces the rapid and reversible collapse of retinal growth cones grown on either of two distinct adhesion substrata, mouse laminin or the chick cell surface axonal glycoprotein G4/NgCAM. The collapsing activity is inhibited by several different types of serine proteinase inhibitors, including the irreversible inhibitor PPACK (D-phenylalanyl-prolyl-arginine chloromethyl ketone). The activity is not inhibited by the specific thrombin inhibitor, hirudin. We have named the adrenal derived collapsing activity erase. PPACK blocks the collapse of temporal retinal growth cones on contact with DRG neurites, but does not block the collapse of the same growth cones on contact with nasal retinal neurites. These results support the hypothesis that a serine proteinase on peripheral axons serves as an avoidance cue which induces contact mediated collapse of retinal growth cones.
\end{abstract}

[Key words: serine protease, serine proteinase, growth cone guidance, thrombin, growth cone collapse, growth cone repulsion, neurite retraction, protease inhibitor, proteinase inhibitor, inhibition of locomotion, inhibition of motility]

There is now considerable evidence that growth cones are sometimes guided away from inappropriate regions or pathways by specific avoidance cues. Although a wide variety of these repulsive activities have been defined using in vitro assays, it has been more difficult to characterize them at a molecular level. Here we show that an avoidance cue on peripheral axons that induces retinal ganglion cell growth cones to collapse (Kapfhammer and Raper, 1987b) is likely to be a serine proteinase that we have named erase.

The growth cones of retinal ganglion cells respond to at least two distinct avoidance cues. One cue specifically affects ganglion cell growth cones that originate from the temporal half of

\footnotetext{
Received Dec. 8, 1994; revised May 25, 1995; May 31, 1995

We thank R. Pittman for his suggestions regarding proteinase inhibitors and $S$. Chang for her advice concerning the purification of $\mathrm{G} 4$ protein. We thank Jinhong Fan for help with the videomicroscopy and all the members of the lab for their support and assistance. J.L.B. is a Howard Hughes Medical Institute Preductoral Fellow. This work was supported by grants to J.A.R. from the NIH and the McKnight Foundation.

Correspondence should be addressed to Jonathan A. Raper at the above address.

Copyright (C) 1995 Society for Neuroscience $0270-6474 / 95 / 156605-14 \$ 05.00 / 0$
}

the retina, while the second affects ganglion cell growth cones that originate from both halves of the retina.

A temporal specific cue was first demonstrated by Bonhoffer and Huf (1985) who used an in vitro assay to show that chick temporal retinal ganglion cells prefer to extend on temporal as compared to nasal retinal axons. This selective fasciculation may be explained by the observation that temporal retinal ganglion cell growth cones collapse on contact and are repelled by nasal but not temporal retinal axons in culture (Raper and Grunewald, 1990). Similiarly, chick temporal retinal growth cones, but not nasal growth cones, avoid stripes of plasma membranes prepared from the posterior optic tectum (Walter et al., 1987). Temporal but not nasal growth cones collapse and become paralyzed when exposed to extracts of posterior tectal membranes (Cox et al., 1990). The function of this posterior avoidance cue may be to discourage temporal retinal growth cones from extending posteriorly beyond their normal anterior target region in the optic tectum. Finally, retinal growth cones from the ventral temporal region in mouse retina, whose axons are the only retinal axons to project within the ipsilateral optic tract, appear to be specificaly repelled by the midline region of the optic chiasm (Godement et al., 1990; Sretavan, 1990; Sretavan and Reichardt, 1993; Wizenmann et al., 1993). This interaction apparently prevents these growth cones from crossing over into the contralateral optic tract. The selective sensitivity of temporal retinal ganglion cell growth cones to inhibitory stimuli in each of these assays suggests that the same avoidance cue could be responsible for each of the observed behaviors.

A second avoidance cue that retinal ganglion cell growth cones respond to has been described by Kapfhammer and Raper (1987b). Both nasal and temporal retinal ganglion cell growth cones collapse and become temporarilly paralyzed on contact with neurites from cultured dorsal root ganglia (DRG), sympathetic ganglia, or ciliary ganglia (Kapfhammer and Raper, $1987 a, b)$. Since there is no difference in the relative sensitivity of nasal and temporal growth cones to contact with peripheral neurites, it is reasonable to assume that the avoidance cue involved is distinct from the tectal, chiasmatic, or nasal cues just described. In contrast to the collapse of retinal growth cones on contact with peripheral axons, growth cones from any of the peripheral tissues do not collapse when they contact any of the other peripheral neurites. Kapfhammer and Raper (1987b) therefore proposed that peripheral neurites express an avoidance cue that all retinal ganglion cell growth cones respond to and that peripheral growth cones ignorc.

The membranes of PC12 cells have been found to express a growth cone collapsing activity that collapses retinal growth cones but not DRG growth cones (Raper and Kapfhammer, 
1990). Since PC12 cells are derived from an adrenal tumor, a tissue derived from neural crest and closely related to sympathetic neurons, adrenals are a potential plentiful source of the cue on peripheral axons that repulses retinal growth cones.

In this study we have used plasma membranes prepared from newborn calf adrenals as a source of growth cone collapsing activity. We have found that they contain an activity, like the PC12 derived activity, that is more effective in collapsing CNS growth cones as compared to PNS growth cones. It induces rapid and reversible collapse that does not depend on the substratum on which the test growth cones extend. The adrenal derived collapsing activity is probably a serine proteinase because its effects are inhibited by a number of different classes of serine proteinase inhibitors. We have named this activity erase.

Moreover, the collapse of retinal ganglion cell growth cones on contact with DRG neurites is blocked by the most selective of the irreversible serine proteinase inhibitors that blocks erase activity. This inhibitor does not simply interfere with the mechanism of growth cone collapse since it has no effect on the collapse of temporal retinal growth cones that contact nasal retinal neurites. These results suggest that the avoidance cue on DRG axons which induces the collapse of retinal ganglion cell growth cones is a serine proteinase similar or identical to erase.

\section{Materials and Methods}

Materials. Human two-chain tissue plasminogen activator $(78,000 \mathrm{IU} /$ $\mathrm{mg}$ protein) and one chain urokinase $(80,000 \mathrm{IU} / \mathrm{mg}$ protein) were obtained from American Diagnostica, PPACK from Aminobiotech Ltd., mouse laminin from GIBCO, and nerve growth factor and ITS premix from Collaborative Research. Bovine thrombin had a specific activity of 1630-2100 NIH U/mg protein (Sigma \#T 7513). Bovine Factor Xa had a specific activity of $500 \mathrm{U} / \mathrm{mg}$, and bovine Factor II had a specific activity of $5 \mathrm{U} / \mathrm{mg}$. The specific activity of bovine Factor Xa (Sigma \#B 6003) was defined by the supplier as the amount of activity, measurcd by substrate clotting time, that would be seen with one unit of Factor X activated in the presence of Russel's viper venom. One unit of either Factor X or Factor II was defined as the amount of that factor found in $1 \mathrm{ml}$ of normal human plasma. TLCK, TPCK, soybean trypsin inhibitor, aprotinin $(9700 \mathrm{KIU} / \mathrm{ml})$, leupeptin, antithrombin III (360 $\mathrm{U} / \mathrm{mg}$ protein), recombinant leech hirudin $(8500 \mathrm{U} / \mathrm{mg}$ protein), and $N$ $p$-tosyl-Gly-Pro-Arg $p$-nitroanilide were all obtained from Sigma. PMSF was a gift from Randall Pittman. It was originally obtained from Sigma and was further purified by ethanol precipitation before use. DFP was obtained from Aldrich. Specific activities of all proteinases are reported as provided by the suppliers and were not independently verified. $\Lambda$ monoclonal antibody that recognizes chick $\mathrm{G} 4$ was a gift of Fritz Rathjen. The CSAT antibody that recognizes the integrin $\beta_{1}$ subunit was a gift of David Boettinger.

Cultured tissues. Dorsal root ganglia were dissected from embryonic day 7 (E7) chick embryos. Neural retinae from the temporal or nasal halves of the eye and ciliary ganglia were dissected from E6 chick embryos. Diencephalic and tectal explants were made from E5 embryos. Sympathetic ganglia were dissected from E9 embryos. Ganglia were cut into halves or thirds. Retinal, diencephalic and tectal explants were approximately $0.5 \mathrm{~mm}^{2}$ in size. The optic fissure was used as a landmark to separate temporal and nasal halves of the retina. The middle onethird of the retina was discarded and only the lateral most thirds of the nasal or temporal retinae were used to make explants. For the video recorded encounters between temporal retinal growth cones and various neurites, explants were spaced 2-3 mm apart from one another. Cultures were incubated at $37^{\circ} \mathrm{C}$ in $5 \% \mathrm{CO}_{2}$ All videos were made between $16-$ $20 \mathrm{hr}$ after explantation.

Culture substrata. Ten millimeter glass coverslips were washed with nitric acid, silanized, and coated with EHS laminin at a concentration of $40 \mu \mathrm{g} / \mathrm{ml}$ for $1 \mathrm{hr}$ as described previously (Kapfhammer et al., 1986). Chick G4 was isolated from plasma membranes of E16 and E17 chick brains (Rathjen et al., 1987) and $45 \mu \mathrm{g} / \mathrm{ml}$ applied to silanized coverslips for $1 \mathrm{hr}$ at room temperature In the experiments with $\mathrm{G4}$, both G4 and laminin coated coverslips were blocked with $3 \mathrm{mg} / \mathrm{ml} \mathrm{hemo-}$ globin and then extensively washed with $\mathrm{Ca}^{2+} \mathrm{Mg}^{+2}$ free Hanks' Balanced Salt Solution (CMF-HBSS).

Culture media. Explants were cultured 18-24 hr in F-12 medium (J R H Biosciences) supplemented as in Bottenstein et al. (1980) plus 100 $\mu \mathrm{g} / \mathrm{ml}$ bovine pituitary extract, $2 \mathrm{~mm}$ glutamine, $100 \mathrm{U} / \mathrm{mll}$ penicillin, $100 \mu \mathrm{g} / \mathrm{ml}$ streptomycin, and $20 \mathrm{ng} / \mathrm{ml}$ mouse $7 \mathrm{~S}$ NGF. Because serum contains antithrombin III and other serine proteinase inhibitors that may affect the adrenal derived activity, we have replaced serum in our culture medium with bovine pituitary extract. All data presented here, with the exception of Figure $2 B$, are from experiments performed in the absence of serum. Bovine pituitary extract was prepared from mature bovine pituitaries (Pelfreez) as described by Tsao et al. (1982) with minor modifications. Rriefly, pituitaries were thawed in water, washed, and trimmed. They were then extracted in $2.4 \mathrm{ml}$ of CMF-HBSS per gram of tissue by homogenization in a blender at moderate speed for a total of 10 min using fivc pulscs with brief rests between pulses to allow the extract to cool. The extract was stirred for $90 \mathrm{~min}$ at $4^{\circ} \mathrm{C}$ and then centrifuged at $24,000 \times g$ for $30 \mathrm{~min}$. The resulting supernatant was dialysed against 20 volumes of PBS twice for 4 or more hours and then additionally dialyzed against 10 volumes of F-12 medium overnight. The bovine pituitary extract was spun at $100,000 \times g$ for $1 \mathrm{hr}$ prior to filtration through $0.2 \mu \mathrm{m}$ cellulose acetate. Extraction, centrifugation, and dialysis were done at $4^{\circ} \mathrm{C}$. Aliquots of bovine pituitary extract were frozen at $-20^{\circ} \mathrm{C}$ and retained growth supporting activity for a minimum of 3 months. Protein concentrations of bovine pituitary extracts and adrenal extracts were determined according to Bradford (1976).

Preparation of adrenal plasma membrane extract. Fresh adrenal glands from newborn calfs ( $\leq 6 \mathrm{~d}$ old) were packed on ice and obtained the day after slaughter from Pelfreez. Fat and connective tissue were trimmed away, the glands were minced with razor blades and then homogenized in a dounce homogenizer with CMF-HBSS containing 20 $\mathrm{mm}$ HEPES $\mathrm{pH} 7.4,2 \mathrm{~mm}$ EDTA, $50 \mu \mathrm{M}$ leupeptin, and $200 \mathrm{KIU} / \mathrm{ml}$ aprotinin. A fraction enriched for plasma membranes was prepared by discontinuous sucrose density centrifugation (Raper and Kapfhammer, 1990). Briefly, the adrenal homogenate was centrifuged at $16,000 \times g$ and washed twice with CMF-HBSS containing $20 \mathrm{~mm}$ HEPES pH 7.4 and $2 \mathrm{~mm}$ EDTA. The resulting pellet was resuspended in 2 volumes of $2.25 \mathrm{M}$ sucrose in PBS to give a final concentration of $1.5 \mathrm{M}$ sucrose. This was layered onto a $2.25 \mathrm{M}$ sucrose cushion, overlayed with CMFHBSS, $20 \mathrm{~mm}$ HEPES pH 7.4, and 2 mM EDTA, and spun at 16,000 $\times g$ for $30 \mathrm{~min}$. The membranes were removed from the interface of the CMF-HBSS and $1.5 \mathrm{M}$ sucrose layers and washed three times with CMF-HBSS containing $20 \mathrm{~mm}$ HEPES pH 7.4 and 2 mM EDTA. Extracts were prepared by thawing an aliquot of packed membranes at room temperature and homogenizing them in twice their volume of PBS containing 5\% Chaps and $20 \mathrm{~mm}$ HEPES $\mathrm{pH} \mathrm{7.4.} \mathrm{The} \mathrm{extracts} \mathrm{were}$ centrifuged at $100,000 \times g$ for $1 \mathrm{hr}$ and the pellets discarded. Detergent was removed from the extracts before use in the collapse assay by dialyzing the supernatant twice against 500 volumes of PBS for 4-16 $\mathrm{hr}$ each (20 hr total) and then against 100 volumes of F-12 medium for at least $4 \mathrm{hr}$.

Collapse assay. Dialyzed extracts were added to explant cultures in volumes not exceeding $10 \%$ of the total volume of the medium $(\leq 50$ $\mu l$ in $500 \mu 1$ ). Cultures were incubated with the adrenal extract for 1 $\mathrm{hr}$ and then fixed with $4 \%$ paraformaldehyde in PBS pH 7.4 containing $10 \%$ sucrose. Coverslips were mounted onto petriperm dishes (Heraeus) and viewed with a $40 \times$ phase objective. Growth cones at the periphery of explants were scored for collapse if they were not in contact or close proximity to other growth cones or neurites. Growth cones contacting other growth cones or neurites were not scored. A growth cone without lamellipodia was scored as collapsed. In comparing the activity between different conditions the protein concentrations that caused $50 \%$ of the test growth cones to collapse were compared. In those cases where one test group never achieved a level of 50\% collapse, the maximal level of collapse achieved by the least affected sample was used as the comparison point.

Treatment with proteinase inhibitors. For the irreversible inhibitors, $10 \mu \mathrm{M} N$-p-tosyl L-lysine chloromethyl ketone (TLCK), $10 \mu \mathrm{M} N$-tosyl L-phenylalanine chloromethyl ketone (TPCK), 10-100 $\mu \mathrm{M} p$-nitrophenyl $p^{\prime}$-guanidinobenzoate (NPGB), $10 \mu \mathrm{M}$ diisopropyl fluorophosphate (DFP), $10 \mu \mathrm{M}$ phenylmethylsulfonyl fluoride (PMSF), and $1 \mathrm{nM}-10 \mu \mathrm{M}$ D-phenylalanyl L-prolyl L-arginyl chloromethyl ketone (PPACK), inhibitor was incubated with the extract for one hour at room temperature prior to removal of detergent from the extract. Control extracts were 
treated identically to inhibitor treated extracts with vehicle buffer in place of inhibitor. Both detergent and excess inhibitor were then removed by dialyzing the supernatant twice against 500 volumes of PBS for $4-16 \mathrm{hr}$ each $(20 \mathrm{hr}$ total $)$ and then against 100 volumes of F-12 medium for at least 4 norre hours before using the extracts in the collapse assay. Each extract was dialyzed seperately from all others. The medium against which each treated extract was dialyzed was also tested for collapsing activity. A collapsing response from this control would suggest that trace amounts of inhibitor left in the matching inhibitor treated extract could induce a confounding collapse response of its own. For the reversible inhibitors, aprotinin $(200 \mathrm{KIU} / \mathrm{ml})$, leupeptin $(50 \mu \mathrm{M})$, soybean trypsin inhibitor $(200 \mu \mathrm{g} / \mathrm{ml})$, antithrombin III $(1.25 \mathrm{U} / \mathrm{ml})$, or hirudin $(5 \mathrm{U} / \mathrm{ml})$ were added to both the cultured explants and the test extract $15 \mathrm{~min}$ before using the extract in the collapse assay. The control for these experiments was to add the appropriate buffer without inhibitors to both the adrenal extract and the test culturc.

The effectiveness of added inhibitors are expressed as the amount by which they shifted the concentration of adrenal extract that yielded a given level of growth cone collapse. Inhibitors that induced shifts of less than $20 \%$ were considered to be ineffective.

Enrichment of activity by anion exchange chromatography. For the experiment shown in Figure 6, we used adrenal membrane derived activity that had been enriched by anion exchange chromatography. This was necessary because the crude extract contained particulate matter that partially obscured the test growth cones being videorecorded. Detergent extracts of adrenal membranes were prepared as before except that membranes were first washed with a low salt buffer of $10 \mathrm{~mm}$ Tris and $10 \mathrm{~mm}$ HEPES $\mathrm{pH} 7.65$, and then extracted in PBS containing 5\% sodium cholate and $20 \mathrm{~mm}$ HEPES pH 7.4. Fresh Q sepharose (fast flow, Sigma) was alternately washed with $0.5 \mathrm{~m} \mathrm{NaCl}$ containing $0.1 \%$ sodium cholate and $20 \mathrm{~mm}$ HEPES $\mathrm{pH} 7.4$, then $10 \mathrm{~mm}$ Tris and 10 mM HEPES $\mathrm{pH} 7.65$, followed by $0.5 \mathrm{M} \mathrm{NaCl}$ containing $0.1 \%$ sodium cholate and $20 \mathrm{mM}$ HEPES $\mathrm{pH} 7.4$ and finally preequilibrated with extraction buffer. Column bed volume was $1 / 4$ to $1 / 3$ extract volume. Extract was centrifuged at $100,000 \times g$ for $1 \mathrm{hr}$ at $4^{\circ} \mathrm{C}$ and the supernatant was then applied to the $Q$ column. The column was washed with 10 column volumes of PBS containing $0.1 \%$ sodium cholate and 20 mM HEPES pH 7.4 and eluted with $0.5 \mathrm{M} \mathrm{NaCl}$ containing $0.1 \%$ sodium cholate and $20 \mathrm{~mm}$ HEPES $\mathrm{pH} 7.4$. The first 0.3 column volumes of eluate was discarded and 3 column volumes of eluate were retained. Q eluate was dialyzed twice against 500 volumes of PBS for a total of 20 $\mathrm{hr}$, once against 100 volumes of $\mathrm{F}-12$ for a miniumum of $4 \mathrm{hr}$, and then applied to explant cultures which had been prepared for video recording. $Q$ eluates prepared in this manner were enriched for retinal growth cone collapsing activity $30-140$-fold as measured separately by the usual collapse assay.

Video microscopy. Two to six hours prior to being moved to a heated stage for viewing, the culture medium was replaced by $2.5 \mathrm{ml}$ of $\mathrm{CO}_{2}$ independent medium identical to the growth medium with the exception that $20 \mathrm{~mm}$ HEPES pH 7.4 replaced the $\mathrm{NaHCO}_{3}$. The culture medium was overlaid with $1 \mathrm{ml}$ of mineral oil preequilibrated with F12 medium to prevent evaporation of the medium during filming. Images were recorded at 1-5 min intervals as described in Fan et al. (1993). Growth cones were viewed by phase contrast through a $40 \times$ Plan lens and the image further magnified by $1.6 \times$ Optovar on an Axiovert 35 (Zeiss). For the experiments shown in Figure 6 , thrombin $(120 \mu \mathrm{l}$ at $50 \mathrm{U} / \mathrm{ml})$ or $120 \mu \mathrm{l}$ of $\mathrm{Q}$ eluate (dialyzed against F12) was added to $380 \mu \mathrm{l}$ of the $\mathrm{CO}_{2}$ independent medium preequilibrated at $37^{\circ} \mathrm{C}$ and then introduced to the culture dish at several points. A solution of $0.05 \%$ Coomassie brilliant blue takes about $10 \mathrm{~min}$ to completely disperse when added in a similar fashion.

Collection of data and treatment with inhibitors for video recorded encounters between temporal retinal growth cones and various neurites. Fields were chosen for video recording that were as free as possible from additional interfering growth cones or neurites. The angle of approach between growth cones and axons was chosen to be $45^{\circ}$ or greater because shallow angle encounters often do not lead to full collapse (Fan and Raper, 1995). Data from encounters in which a test growth cone contacted another growth cone were discarded. Data were also discarded if the test growth cone encountered a second neurite before reaching the arbitrary fixed crossover point of $8 \mu \mathrm{m}$. Only one crossover per test growth cone was used in the analysis of data even for growth cones that crossed additional neurites. The one exception to this rule was made for some temporal retinal growth cones that crossed temporal neurites well before encountering test DRG or nasal retinal neurites. In these few cases, the encounter with the temporal neurite was also analyzed for inclusion in the controls. The growth cone was filmed for a minimum of 60 min beyond the predicted time of crossover, or until crossover itself, whichever occurred first.

For encounters recorded in the presence of $50 \mu \mathrm{M}$ PPACK, $15 \mu \mathrm{l}$ of $10 \mathrm{mM}$ PPACK (Aminobiotech) in $1 \mathrm{mM} \mathrm{HCl}$ was added to $485 \mu \mathrm{l}$ of the $\mathrm{CO}_{2}$ independent medium preequilibrated at $37^{\circ} \mathrm{C}$ and introduced to the culture dish at several places. For encounters in the presence of 5 $\mathrm{U} / \mathrm{ml}$ hirudin, a $6 \times$ solution of hirudin was prepared from $30 \mu l$ of a $500 \mathrm{U} / \mathrm{ml}$ stock of lyophilized hirudin (Sigma) dissolved in $470 \mu \mathrm{F} 12$ medium. We determined that PPACK must be added a minimum of 20 min prior to contact with the test neurite to be effective. Early data collected with insufficient incubation time were discarded. A $10 \mathrm{~min}$ minimum preincubation time was used for encounters recorded in the presence of hirudin since longer preincubation times were found to give the same results as shorter times. The half lifes of PPACK and hirudin under these culture conditions were determined by assaying their ability to inhibit thrombin in an in vitro colorometric assay using $N$-p-tosylGly-Pro-Arg $p$-nitroanilide as a substrate (Lottenberg et al., 1981). PPACK had a half-life of between 1 and $2 \mathrm{hr}$. Hirudin retained $75 \%$ of its thrombin inhibiting activity for up to $4 \mathrm{hr}$. Erase is very effectively inhibited by incubating it for $1 \mathrm{hr}$ at room temperature with $10 \mu \mathrm{M}$ PPACK. We used $50 \mu \mathrm{M}$ PPACK in these experiments to assure that a sufficient concentration of PPACK was present for the duration of the filming period. Aliquots of inhibitor stocks were made and kept frozen at $-70^{\circ} \mathrm{C}$ and thawed immediately before their use.

Analysis of encounters. Each video recording was converted into a graph relating the distance in mirometers between the growth cone and the neurite in its path as a function of time in minutes. Distance was measured from a point at the approximate center of the lamellipodia of the growth cone to the point on the neurite where the growth cone eventually contacts it. To reduce the contribution of variations in growth cone speed and size to the analysis, we compared how long each gruwth cone was delayed by contact with a neurite. The average speed of the growth cone at the time of contact was estimated from the position versus time plot. The time at which the center of the growth cone would be predicted to pass $8 \mu \mathrm{m}$ past the neurite was estimated from the average speed of advancement before contact. The predicted time of crossover was compared to the actual time of crossover to determine how long the growth cone was delayed by contact with the neurite. In measuring the lagtime between contact and the initiation of collapse, the time at which the lamellipodia made contact with the neurite was considered the time of contact because filapodial contact alone was seldom a sufficient stimulus to induce collapse.

\section{Results}

A serine proteinase collapses $C N S$ growth cones

Extracts from adrenal membranes collapse CNS growth cones better than PNS growth cones. Detergent extracts of newborn calf adrenal plasma membranes that have had the detergent removed by dialysis, induce the collapse of retinal growth cones but have little effect on DRG growth cones (Fig. 1). Retinal growth cones are at least 5-15-fold more sensitive to the adrenal extract than are DRG growth cones. Adrenal membrane extracts also effectively collapse growth cones from both chick diencephalic and tectal explants but have little effect on either ciliary or sympathetic growth cones (data not shown). The ability of adrenal derived collapsing activily to affect CNS growth cones in preference to PNS growth cones is similar to that expected for the hypothetical peripheral axonal label.

Adrenal derived collapsing activity acts rapidly and is reversible. Near maximal levels of retinal growth cone collapse are seen within $15 \mathrm{~min}$ of exposure to the adrenal extract (Fig. $2 A$ ). The percentage of collapsed growth cones remains constant for at least $4 \mathrm{hr}$. The assay does not distinguish between growth cones that have remained collapsed for $4 \mathrm{hr}$ and those which have collapsed more recently, so we cannot conclude that a given growth cone remains collapsed for the entire $4 \mathrm{hr}$ period, only that the percent of affected growth cones remains stable. If the extract is applied for $30 \mathrm{~min}$ and then washed out with three 


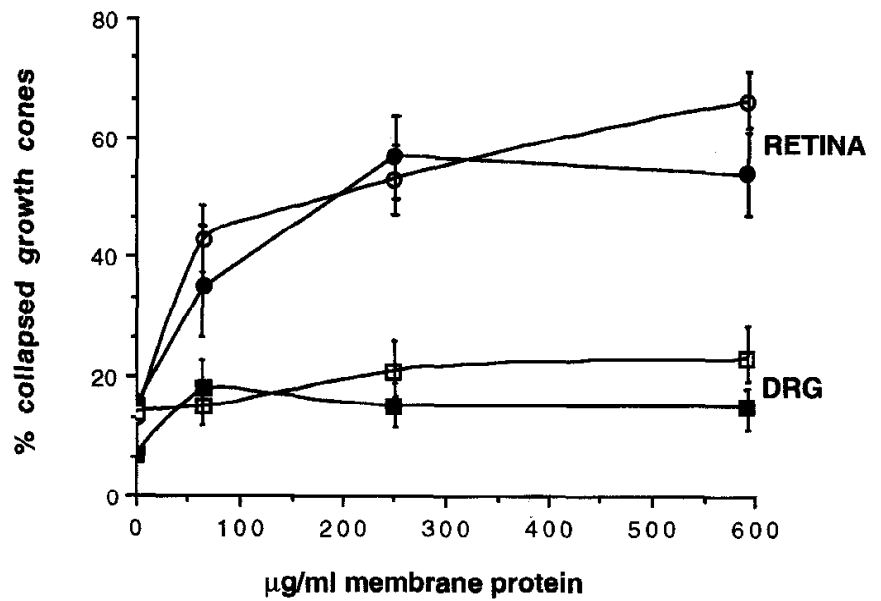

Figure 1. Adrenal extract collapses retinal ganglion cell growth cones better than DRG growth cones. Retinal and DRG explants were grown on silanized coverslips that had been incubated for $1 \mathrm{hr}$ at room temperature with either $40 \mu \mathrm{g} / \mathrm{ml}$ mouse laminin or $45 \mu \mathrm{g} / \mathrm{ml}$ chick G4 protein and then blocked with $3 \mathrm{mg} / \mathrm{ml}$ hemoglobin. Detergent extracts of plasma membranes isolated form newborn bovine adrenals were applied to serum-free chick retina (circles) or DRG (squares) explant cultures after removal of detergent by dialysis. Cultures were fixed one hour after addition of extract and scored for collapsed and intact growth cones. The adrenal extract has the same level of collapsing activity towards retinal growth cones extending on either laminin (open circles) or G4 protein (solid circles). It has little collapsing activity towards DRG growth cones extending on either laminin (open squares) or G4 protein (solid squares). Error bars indicate 95\% confidence limits of the means estimated using the assumption that the data are distributed according to a binomial distribution.

changes of medium, collapsed growth cones recover their spread morphology. The percentage of collapsed growth cones approaches control levels within $30 \mathrm{~min}$ after washout (Fig. 2B). The response of growth cones to the adrenal extract is therefore rapid, long lasting, and reversible.

The adrenal derived collapsing activity is reduced by serine proteinase inhibitors. Collapsing activity was lost when $10 \mu \mathrm{M}$ of the irreversible serine hydrolase inhibitor $p$-nitro $p^{\prime}$-guanidinobenzoate (NPGB) was added to the cocktail of proteinase inhibitors present during the preparation of adrenal membranes. Treatment of the adrenal membrane extract with $100 \mu \mathrm{M}$ NPGB for $1 \mathrm{hr}$ at room temperature, followed by dialysis to remove excess inhibitor, inhibited $95 \%$ of the growth cone collapsing activity of the extract (Fig. 3A). Similar treatment with $10 \mu \mathrm{M}$ diisopropyl fluorophosphate (DFP) decreased the collapsing activity of the adrenal extract to $46 \%$ of control values, and treatment with $10 \mu \mathrm{M}$ phenylmethylsulfonyl fluoride (PMSF) decreased collapsing activity to $29 \%$ of control values (data not shown). Inhibition of growth cone collapsing activity by three chemically distinct serine hydrolase inhibitors suggests that the adrenal derived activity is a serine hydrolase and could be either a proteinase or an esterase.

In order to identify the class of serine hydrolase that the adrenal derived collapsing activity belongs to, we screened a number of serine proteinase inhibitors for their ability to decrease the growth cone collapsing activity of the adrenal extract (Table 1). The inhibitors selected are effective against different subsets of serine proteinases. For example $N$-tosyl phenylalanine chloromethyl ketone (TPCK) is an active site directed inhibitor that has Phenylalanine at the amino side of the mock scissile bond (the $\mathrm{P}_{1}$ site by the nomenclature of Schechter and Berger, 1967).

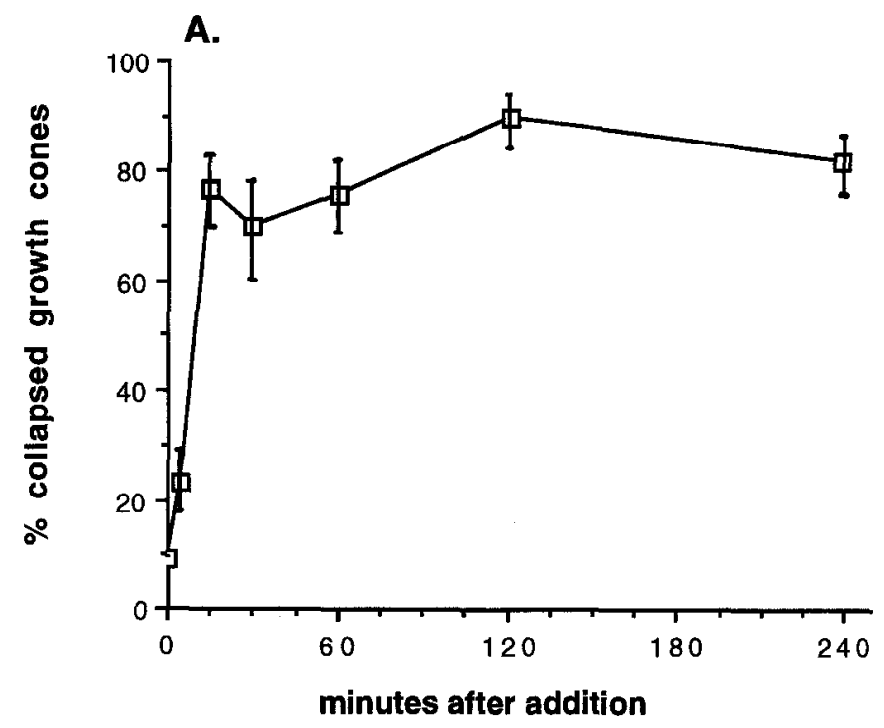

B.

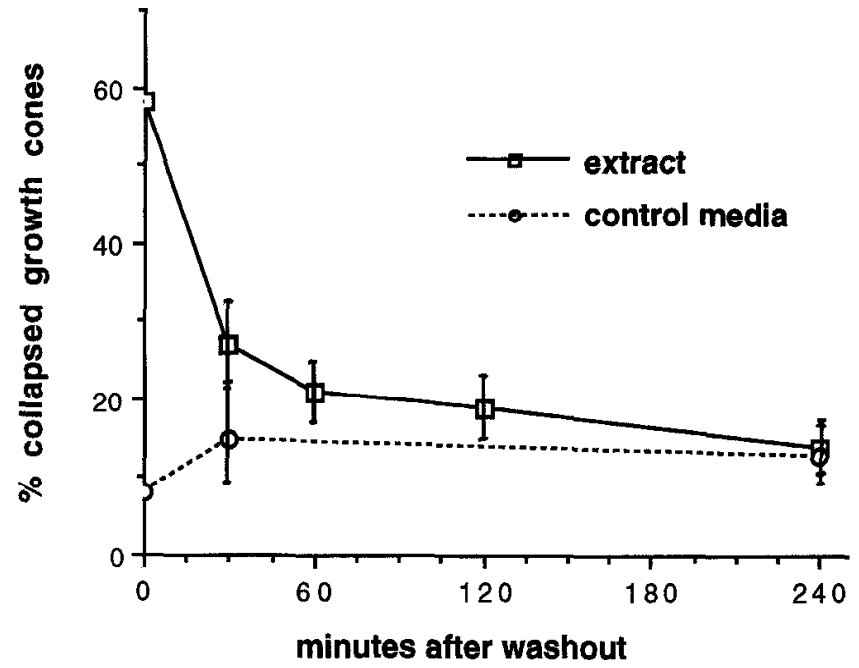

Figure 2. Adrenal extract causes rapid and reversible collapse. A, Adrenal extract $(430 \mu \mathrm{g} / \mathrm{ml})$ was added to retinal explant cultures at various time points prior to fixation and the fixed cultures were then scored for collapse. $B$, Retinal cultures were treated with $1.15 \mathrm{mg} / \mathrm{ml}$ adrenal extract for $30 \mathrm{~min}$ (solid squares) or F12 medium (open circles). Extract was removed from the cultures by washing them three times with serum-containing media. Explants were fixed at various time points after washing and then scored for collapse. Control cultures were subjected to the same washes as extract treated cultures. The zero time points are from treated but unwashed wells. Error bars indicate $95 \%$ confidence limits of the means estimated using the assumption that the data are distributed according to a binomial distribution.

TPCK inhibits chymotrypsin-like serine proteinases but not trypsin-like or elastase-like serine proteinases. PPACK and $N$-tosyl lysine chloromethyl ketone (TLCK) are active site directed irreversible inhibitors with the basic amino acids arginine or lysine, respectively, in the $\mathrm{P}_{1}$ site. They inhibit trypsin-like but not chymotrypsin-likc or elastasc-like scrinc proteinases.

We found that pretreatment of the adrenal extract with the irreversible inhibitor PPACK at $1 \mathrm{nM}, 100 \mathrm{nM}$, and $10 \mu \mathrm{M}$ for 1 $\mathrm{hr}$ at room temperature inhibited the adrenal derived collapsing 

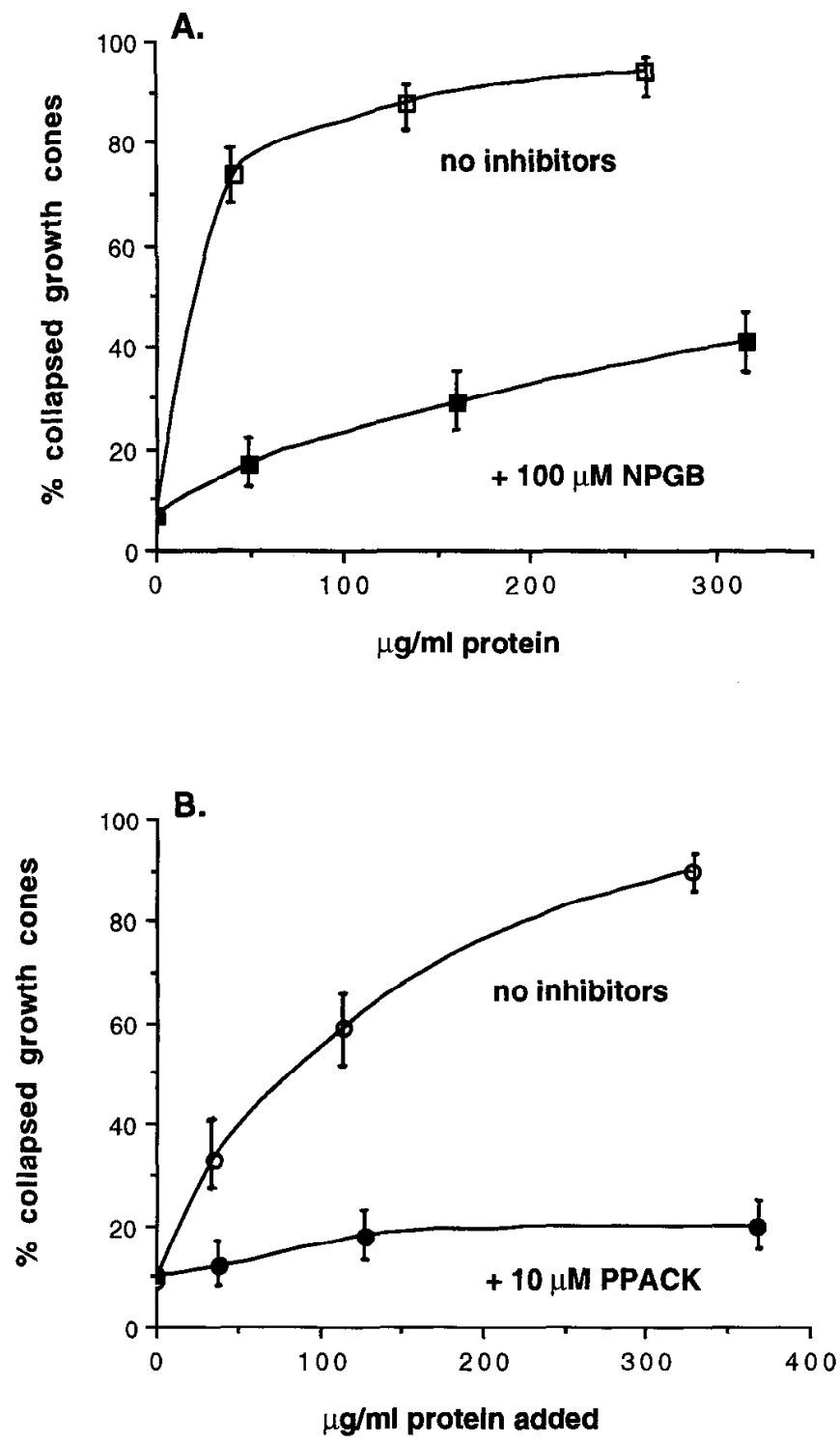

Figure 3. Adrenal derived collapsing activity is inhibited by serine proteinase inhibitors. $A$, Adrenal extract was incubated for $1 \mathrm{hr}$ at room temperature with $100 \mu \mathrm{M}$ NPGB (solid squares) or F12 medium (open squares) prior to dialysis and then applied to retinal explant cultures. $B$, Adrenal extract was incubated for $1 \mathrm{hr}$ at room temperature with 10 $\mu \mathrm{M}$ PPACK (solid circles) or F12 (open circles) prior to dialysis and then applied to retinal explant cultures. Error bars indicate $95 \%$ confidence limits of the means estimated using the assumption that the data are distributed according to a binomial distribution.

activity $59 \%, 90 \%$, and $96 \%$ (Fig. 3B). This suggests that the adrenal derived collapsing activity belongs to the trypsin-like subclass of serine proteinases. Since the irreversible inhibitor $N$-tosyl lysine chloromethyl ketone had no effect on the adrenal derived collapsing activity (Table 1), the adrenal activity is probably a trypsin-like serine proteinase with a preference for arginine in the $P_{1}$ site. While PMSF and PPACK will also inhibit some cysteine proteinases, DFP is thought to only inhibit serine proteinases (Salvesen and Nagase, 1989). Therefore, it is unlikely that the adrenal derived activity is a cysteine proteinase. Several common reversible inhibitors of trypsin-like serine proteinases were also tried. Antithrombin III, a reversible proteinase inhibitor that is found in serum, decreased the adrenal derived activity $50 \%$ when present at a concentration of $1.25 \mathrm{U} / \mathrm{ml}$ (data not shown).

The collapsing activity of the adrenal extract is substratum independent. The adrenal derived collapsing activity was tested for its ability to affect growth cones extending on two different substrata. The extracellular matrix protein EHS laminin was used in our standard assay. In addition, we used as an alternative substratum the cell surface axonal glycoprotein G4/NgCAM (Rathjen et al., 1987). CSAT antibody (Neff et al., 1982), a monoclonal antibody directed against the $\beta_{1}$ subunit of integrin, detaches both retinal and DRG growth cones and axons from laminin but not from G4. A monoclonal antibody directed against G4 (Rathjen et al., 1987) detaches retinal growth cones and axons from $\mathrm{G} 4$ but not from laminin. We therefore infer that both retinal and DRG growth cones grow on these two substrata using independent cell surface receptors. The adrenal derived collapsing activity is equally effective in inducing the collapse of retinal growth cones extending on either laminin or G4 (Fig. 1). It induces little collapse of DRG growth cones extending on either substrate.

A comparison of the adrenal derived collapsing activity with the blood coagulation enzyme thrombin. The adrenal derived collapsing activity can be distinguished from thrombin, a serine proteinase that causes neurite retraction in both CNS and PNS neurons and neuronal cell lines (Hawkins and Seeds, 1986; Gurwitz and Cunningham, 1988; Grand et al., 1989; Jalink and Moolenaar, 1992). We found that the effects of the adrenal derived collapsing activity and thrombin differed in several respects. First, they affected different neural cell types. The adrenal derived activity is more effective in collapsing retinal (Fig. $4 B$ ). as compared to DRG growth cones (Fig. $4 E$ ). In contrast, thrombin affects both equally (Fig. 4C,F). Thrombin also causes retraction of ciliary ganglia neurites while the adrenal derived activity has little effect on these peripherally derived growth cones (not shown). These differences between the effects of the adrenal derived activity and thrombin are not simply due to differences in the potencies of the two proteinases. The same specificities are apparent when using concentrations of thrombin that cause only half of the test neurites to respond. Second, thrombin and the adrenal derived activity differ in their susceptibility to hirudin, a selective inhibitor of thrombin. The addition of $5 \mathrm{U} / \mathrm{ml}$ of hirudin to the culture medium inhibits thrombin induced neurite retraction (Fig. $5 A$ ) but has no effect on the adrenal derived collapsing activity (Fig. $5 B$ ). Third, the degree of neurite retraction is significantly greater for thrombin as compared to adrenal extract treated neurites.

Time lapse video microscopy was used to follow the reaction of retinal growth cones to either the adrenal derived collapsing activity or thrombin. Collapsing activity enriched on an anionexchange column was used in this series of experiments. This enriched activity, like that in the crude adrenal extracts, collapses retinal but not DRG growth cones and is blocked by PPACK. The adrenal derived collapsing activity causes retinal growth cones to collapse in place while inducing minimal shortening of neurites (Fig. $6 A-C$ ). The median retraction of retinal neurites treated with adrenal extract was $18 \mu \mathrm{m}$ in 31 trials (for comparison, the median length of the growth cones is $14 \mu \mathrm{m})$. In contrast, thrombin frequently causes extensive neurite retraction (Fig. 6D-F; note especially the retraction of the bottom neurite of the pair). The median retraction of thrombin treated retinal neurites was $44 \mu \mathrm{m}$ in 15 trials. The probability that the measured thrombin and adrenal extract induced retractions are drawn 
Table 1. Serine proteinase inhibitors assayed for inhibition of adrenal derived collapsing activity

\begin{tabular}{lll} 
Type of inhibitor & $\begin{array}{l}\text { Inhibitors that } \\
\text { decrease adrenal } \\
\text { derived collapsing } \\
\text { activity }\end{array}$ & $\begin{array}{l}\text { Inhibitors with no effect } \\
\text { on adrenal derived collapsing } \\
\text { activity }\end{array}$ \\
\hline $\begin{array}{l}\text { General irreversible inhibitors of serine } \\
\text { hydrolases }\end{array}$ & $\begin{array}{l}\text { NPGB } \\
\mathrm{DFP}^{a} \\
\mathrm{PMSF}^{a, b}\end{array}$ \\
$\begin{array}{l}\text { Active site directed irreversible inhibitors of } \\
\text { serine proteinases }\end{array}$ & $\begin{array}{l}\text { PPCK }^{b} \\
\begin{array}{l}\text { Reversible inhibitors of some serine } \\
\text { proteinases }\end{array}\end{array}$ & $\begin{array}{l}\text { TLCK }^{b} \\
\text { TPCK }^{a, b} \\
\text { Hirudin } \\
\text { Aprotinin } \\
\text { Soybean trypsin inhibitor }\end{array}$ \\
& & Leupeptin
\end{tabular}

NPGB ( $p$-nitrophenyl $p^{\prime}$-guanidinobenzoate) is effective at concentrations of 10-100 $\mu \mathrm{M}$. PPACK ( $N$-tosyl L-phenylalanine chloromethyl ketone) is effective at concentrations of $1 \mathrm{nM}-10 \mu \mathrm{M}$. DFP (diisopropyl fluorophosphate), PMSF (phenylmethylsulfonyl fluoride), TLCK ( $N$-p-tosyl L-lysine chloromethyl ketone), and TPCK (D-phenylalanylL-prolyl-L-arginine chloromethyl ketone) were tested at a single dose of $10 \mu \mathrm{M}$. These irreversible inhibitors were added to adrenal extract prior to dialysis and incubated at room temperature for $1 \mathrm{~h}$. Unreacted inhibitor was removed by dialysis. Controls for each inhibitor were treated with the buffer vehicle identically to inhibitor treated samples. For the reversible inhibitors aprotinin $(200 \mathrm{KIU} / \mathrm{ml})$, leupeptin $(50 \mu \mathrm{M})$, soybean trypsin inhibitor $(200 \mu \mathrm{g} / \mathrm{ml})$, antithrombin III $(1.25 \mathrm{U} / \mathrm{ml})$, and hirudin $(5 \mathrm{U} / \mathrm{ml})$, inhibitor was added to both the cultured explants and the test extracts 15 minutes prior to their use in the collapse assay. Inhibitors were considered ineffective if the specific activities of the inhibitor treated and control extracts differed by less than $20 \%$ (the specific activity is defined as the protein concentration of the extract causing $50 \%$ of the growth cones to collapse).

${ }^{a}$ Have only been assayed in presence of serum.

${ }^{b}$ Will also inhibit some cysteine proteinases.

from a similar population is estimated to be $p<0.001$ by the nonparametric Wilcoxan rank test. The concentrations of thrombin and adrenal extract used in these measurements cause similar levels of collapse in the collapse assay (60-80\%, not shown), so the difference in retraction is not simply due to differences in the potencies of the two enzymes.

We considered the possibility that the adrenal derived activity was prothrombin and that retinal growth cones or explants, but not the DRG growth cones or explants, are able to convert prothrombin to thrombin. In this case, the addition of prothrombin to the culture medium should collapse retinal but not DRG growth cones. We found that prothrombin had little effect on either type of growth cone (data not shown). We considered the possibility that retinal explants but not DRG explants produced prothrombin and that the adrenal derived extract was the prothrombin converting proteinase, Factor $\mathrm{Xa}$. In this case, the addition of Factor Xa should collapse retinal but not DRG growth cones. Factor Xa has little collapsing activity towards either type of growth cone (data not shown).

Cultured rat sympathetic neurons and mouse sensory neurons release both tissue-type and urokinase-type plasminogen activators (Pittman et al., 1989; Seeds et al., 1992). Inhibitors of the plasminogen activators, as well as inhibitory antibodies to urokinase increase neurite outgrowth in serum-free culture (Zurn et al., 1988; Pittman et al., 1989). We therefore tested plasminogen activators for growth cone collapsing activity. Neither human two chain tissue plasminogen activator nor human one-chain urokinase affected retinal or DRG growth cones in the collapse assay at the concentrations tested (data not shown).

Relationship between adrenal derived collapsing activity and a previously descibed peripheral axon label

Peripheral axons express a label that induces retinal ganglion cell growth cones to collapse on contact (Kapfhammer and Raper, $1987 \mathrm{~b}$ ). If the adrenal derived activity is the same as the avoidance cue associated with peripheral neurites, then PPACK should prevent retinal growth cones from collapsing on contact with peripheral neurites, but should not interfere with their response to neurites that express other avoidance cues.

Temporal retinal growth cones cross DRG neurites in the presence of the proteinase inhibitor PPACK. Data were collected by video microscopy from temporal retinal ganglion growth cones that contact DRG or nasal retinal neurites in the absence of proteinase inhibitors (control condition) or in the presence of $50 \mu \mathrm{M}$ PPACK. Under control conditions, temporal retinal growth cones generally collapsed on contact with DRG neurites and were therefore delayed in crossing them by $60 \mathrm{~min}$ or more (second column, Table 2). An example of a typical encounter between a retinal growth cone and a DRG neurite in the absence of PPACK is shown in Figure $7 A-D$. The growth cone was spread and advanced at a steady pace as it approached a DRG neurite (Fig. $7 A$ ). The lamellae of the retinal growth cone contacted the DRG neurite 22 min later (Fig. $7 B$ ). Collapse of the retinal growth cone was initiated 2 min after lamellipodial contact (Fig. 7C). The retinal growth cone collapsed and remained so for more than $2 \mathrm{hr}$ after contact (Fig. 7D). Approximately half of the growth cones that collapsed on contact with DRG axons remained so for more than the minimal $80 \mathrm{~min}$ observation period. The remainder reassembled after $15-75 \mathrm{~min}$ but were rarely seen to cross DRG neurites within the same observation period.

In the presence of $50 \mu \mathrm{M}$ PPACK, almost all temporal retinal growth cones were able to cross DRG neurites within 60 minutes of lamellipodial contact (Table 2). Temporal growth cones crossed DRG neurites without collapsing in more than half of the encounters. An example of this type of response is shown in Figure $7 E-H$. A retinal growth cone approached a DRG neurite (Fig. $7 E$ ). Eleven minutes later it made lamellipodial contact with the neurite (Fig. $7 F$ ). The growth cone did not collapse and continued to advance steadily, crossing the DRG neurite within 

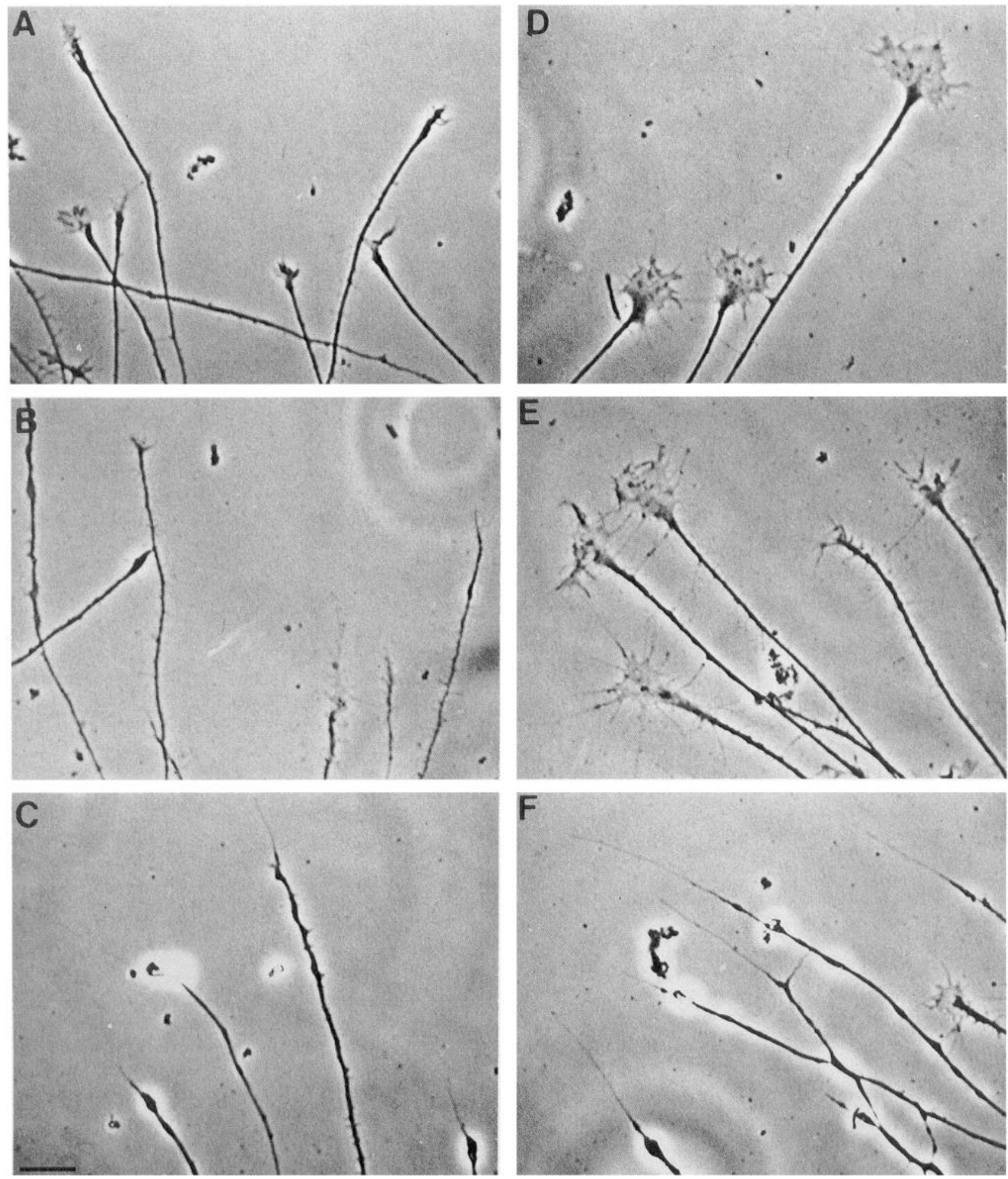

Figure 4. Adrenal extract collapses only retinal growth cones while thrombin affects both retinal and DRG neurites. Retinal explants $(A-C)$ and DRG explants $(D-F)$ were treated with control F12 medium $(A, D), 782 \mu \mathrm{g} / \mathrm{ml}$ of adrenal extract $(B, E)$, or $1 \mathrm{U} / \mathrm{ml}$ thrombin for $1 \mathrm{hr}$ prior to fixation. The total percent collapse for each condition was $13 \%$ for $A, 57 \%$ for $B, 61 \%$ for $C, 3 \%$ for $D, 11 \%$ for $E$, and $57 \%$ for $F$. Scale bar, 20 $\mu \mathrm{m}$.

17 min after first contact (Fig. 2G,H). Some temporal retinal growth cones encountering a DRG neurite in the presence of PPACK collapsed for a brief interval, reassembled, and then crossed the neurite on the second attempt. An example of this kind of interaction is shown in Figure 8. A retinal growth cone collapsed when first contacting a DRG neurite, but later crossed over on a subsequent approach.

PPACK decreases collapse frequency and duration. Since it 

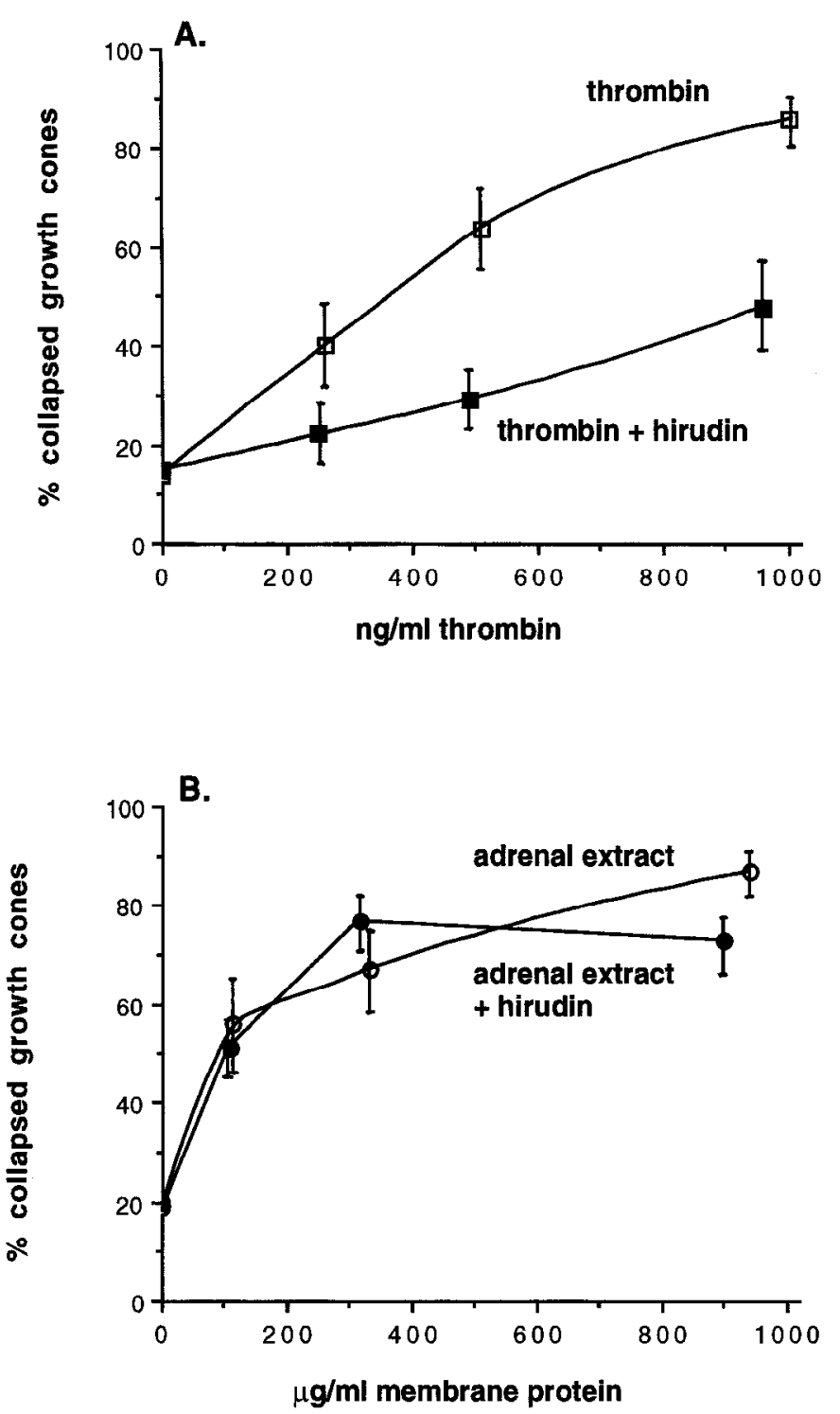

Figure 5. The thrombin inhibitor hirudin inhibits thrombin's action on retinal growth cones but does not inhibit the collapsing activity of adrenal extract on retinal growth cones. $A$, Thrombin's action on retinal neurites is substantially reduced in the presence of $5 \mathrm{U} / \mathrm{ml}$ hirudin. Explants and thrombin were pretreated with hirudin for $15 \mathrm{~min}$ prior to the addition of thrombin. Controls were mock treated with F12 medium. The maximum concentration of thrombin used in the assay was equivalent to 2 coagulation units per ml (manufacturer's measurement). One unit of hirudin is defined as the amount necessary to inhibit 1 unit of thrombin. $B, 5 \mathrm{U} / \mathrm{ml}$ hirudin has no inhibitory effect on the collapsing activity of the adrenal extract on retinal growth cones. Error bars indicate $95 \%$ confidence limits of the means estimated using the assumption that the data are distributed according to a binomial distribution.

is collapse that prevents growth cones from crossing DRG axons, we examined the effect PPACK may have on the frequency and duration of growth cone collapse. If PPACK treatment completely neutralizes the retinal avoidance cue on DRG neurites, the collapse of retinal growth cones that normally occurs on contact with DRG neurites should be completely abolished. Other more subtle aspects of collapse might be affected by incomplete neutralization. As the avoidance cue is weakened, the delay between a growth cone's contact with a DRG neurite and the start of collapse might be expected to lengthen, the duration of collapse might also be expected to decrease, and the likelihood that a collapsed and reformed growth cone crosses the DRG neurite on a second attempt might be expected to increase.

Temporal retinal growth cones encountering DRG neurites in the absence of PPACK gencrally collapsed on first contact, remained collapsed for a long time, and if they recovered, generally collapsed on a second contact (Table 2, Fig. 9A). They therefore were significantly delayed in crossing DRG neurites. Temporal retinal growth cones encountering DRG neurites in the presence of PPACK usually did not collapse on first contact. Those that did collapse were slower to initiate collapse, remained collasped for a relatively brief period of time, and were unlikely to collapse on second contact (Table 2, Fig. 9A). They therefore were likely to experience modest delays when crossing DRG neurites.

Temporal retinal growth cones collapse on contact with DRG neurites in the presence of the thrombin hirudin. PPACK is known to be a very effective inhibitor of thrombin (Kettner and Shaw, 1981). To determine whether PPACK's affects on growth cone collapse might be mediated through an inhibition of thrombin activity, we tested a specific thrombin inhibitor, hirudin, to see if its effects on growth cone collapse are similar to those of PPACK. In the presence of $5 \mathrm{U} / \mathrm{ml}$ hirudin, most temporal retinal growth cones collapsed and did not cross DRG neurites within $60 \mathrm{~min}$ of prediction. There is no statistical difference in the crossover delays of encounters in the absence as compared to the presence of $5 \mathrm{U} / \mathrm{ml}$ hirudin (Table 2, Fig. 9A). We confirmed that hirudin at this concentration is able to prevent the clotting of chick blood, implying that it also inhibits chick thrombin activity (data not showm). The addition of hirudin also had no effect on the frequency or extent of growth cone collapse. Almost all collapsed growth cones that reassembled, collapsed again when they contacted DRG neurites a second time. Hirudin should affect crossover delays in a manner similar to PPACK, if and only if PPACK exerts its effect by inhibition of thrombin. Our results suggest that PPACK's facilitation of retinal crossovers of DRG neurites cannot be ascribed to an inhibitory effect on thrombin.

PPACK does not prevent temporal retinal gowth cones from collapsing on contact with nasal retinal neurites. Could PPACK have a direct effect on the mechanism of growth cone collapse independent of the specific cue that initiates collapse? Similarly, could PPACK simply increase the "robustness" of retinal growth cones so they are less prone to collapse? In either case, PPACK should interfere with the collapse of temporal retinal growth cones collapsing in response to avoidance cues other than that associated with DRG neurites. To explore this possibility, the collapse of temporal retinal growth cones to contact with nasal retinal neurites was examined in the presence and absence of PPACK.

Temporal retinal growth cones collapsed when they contacted nasal retinal neurites and were subsequently delayed from crossing them by more than $60 \mathrm{~min}$ in $73 \%$ of the encounters filmed in the absence of PPACK, and in $71 \%$ of the encounters filmed in the presence of PPACK. PPACK also had no significant effect on the time between first contact and the initiation of growth cone collapse, or on the duration of collapse (Table 2, Fig. 9B). PPACK appears to specifically affect the response of temporal retinal growth cones on contact with DRG neurites. It does not affect the ability of temporal retinal growth cones to collapse in response to the avoidance cue associated with nasal retinal axons. 

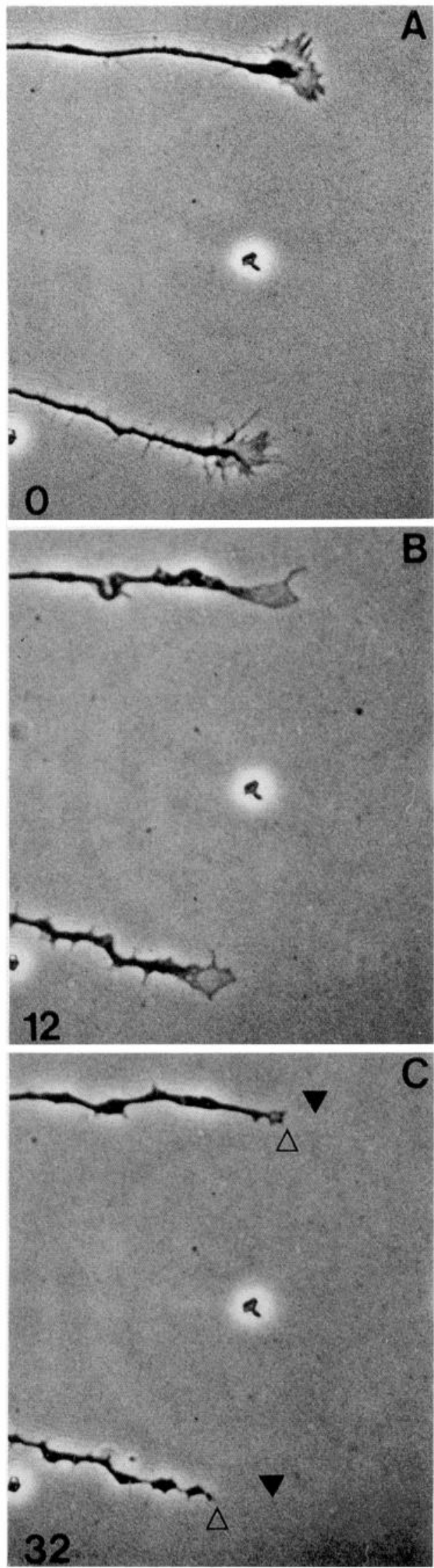
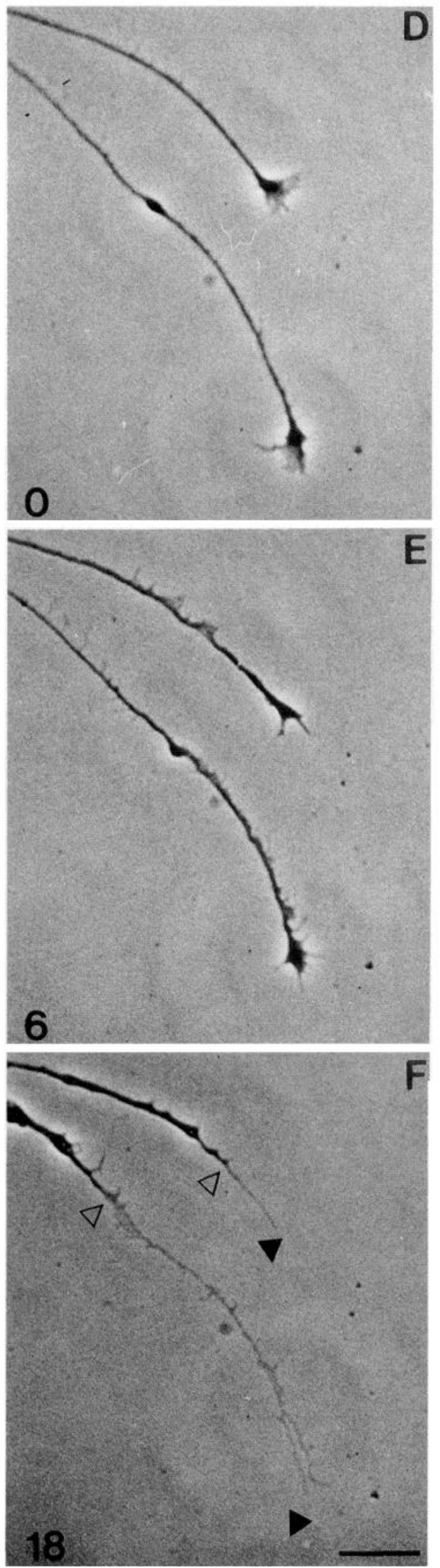

Figure 6. Adrenal extract causes retinal growth cone collapse while thrombin causes collapse and extensive neurite retraction. Retinal explants were treated with adrenal derived collapsing activity enriched $\sim 140$-fold by anion exchange chromatography on $\mathrm{Q}$ sepharose $(A-C)$. $A$ shows two growth cones 1 min prior to addition of $22 \mu \mathrm{g} /$ $\mathrm{ml}$ of $\mathrm{Q}$ eluate. Twelve minutes later both growth cones neared full collapse $(B)$, and $31 \mathrm{~min}$ after addition of extract they have fully collapsed and slightly retracted $(C)$. Retinal explants were treated with $2 \mathrm{U} / \mathrm{ml}$ thrombin $(D$ $F)$. $D$ shows a pair of growth cones 1 min prior to addition of thrombin. Six minutes later the growth cones have collapsed but not yet begun to retract $(E)$ and 17 min after addition of thrombin they have retracted significantly $(F)$. Solid arrowheads in $C$ and $F$ indicate the positions of the growth cones' distal tips in $A$ and $D$, respectively. Open arrowheads indicate the distal tips of the retracted neurites. Scale bar, $20 \mu \mathrm{m}$. 
Table 2. Median crossover delays, collapse frequency, and duration of collapse for temporal retinal ganglion cell growth cones meeting DRG or retinal neurites

\begin{tabular}{|c|c|c|c|c|c|c|c|c|}
\hline $\begin{array}{l}\text { Type of neurite } \\
\text { contacted }\end{array}$ & Inhibitor added & $n$ & $\begin{array}{l}\text { Median } \\
\text { predicted time } \\
\text { to crossover } \\
\text { (min) }\end{array}$ & $\begin{array}{l}\text { Median } \\
\text { crossover } \\
\text { delay (min) }\end{array}$ & $\begin{array}{l}\text { Frequency of } \\
\text { collapse at } \\
\text { first contact }\end{array}$ & $\begin{array}{l}\text { Median } \\
\text { duration } \\
\text { collapse } \\
(\text { min) })^{b, c} \\
\end{array}$ & $\begin{array}{l}\text { Median lag } \\
\text { time to } \\
\text { collapse (Inin) }\end{array}$ & $\begin{array}{l}\text { Frequency of } \\
\text { collapse at } \\
\text { 2nd contact } \\
(n)^{d}\end{array}$ \\
\hline & $50 \mu \mathrm{M}$ PPACK & 19 & 14 & $7 *$ & $41 \%$ & $6^{\text {**k }}$ & $7^{* * *}$ & $17 \%(6)$ \\
\hline & $5 \mathrm{U} / \mathrm{ml}$ hirudin & 19 & 16 & 60 & $100 \%$ & $16 * * *$ & 3 & $92 \%(13)$ \\
\hline Nasal RG & None & 26 & 12 & 60 & $73 \%$ & 13 & 4 & n.a. \\
\hline & $50 \mu \mathrm{M}$ PPACK & 13 & 9 & 5 & $8 \%$ & n.a. & n.a. & n.a. \\
\hline & $5 \mathrm{U} / \mathrm{ml}$ hirudin & 15 & 10 & 2 & $0 \%$ & n.a. & n.a. & n.a. \\
\hline
\end{tabular}

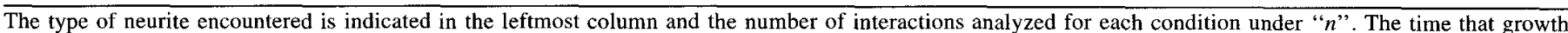

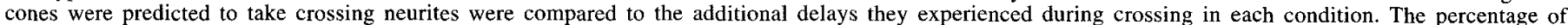

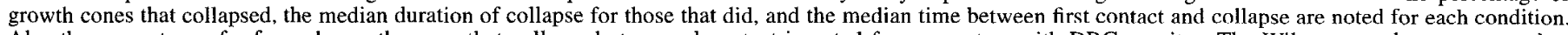

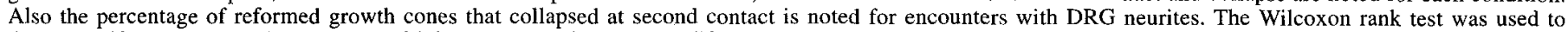

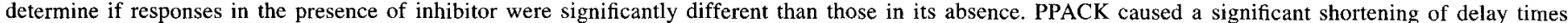

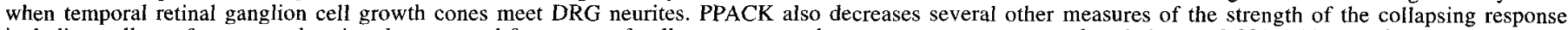

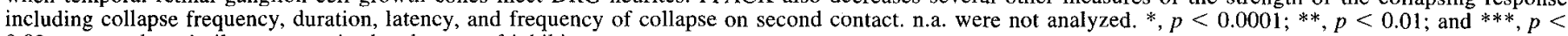
0.02 compared to similar contacts in the absence of inhibitors.

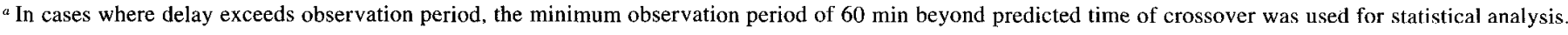
${ }^{\circ}$ Only growth cones that collapsed are included in determining median values and statistical significance.

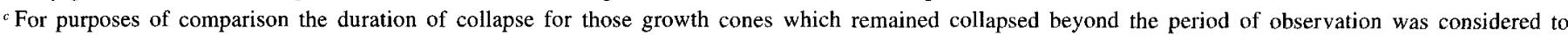
tcrminate at 60 minutes beyond predicted time of crossover.

${ }^{i}(n)$ are the number of growth cones which made multiple contacts.

\section{Discussion}

We have characterized a retinal ganglion cell growth cone collapsing activity derived from the plasma membranes of adrenals. The biological and biochemical profile of this collapsing activity is distinct from those of other known collapse inducing molecules. Luo et al. (1993) recently isolated and sequenced collapsin, a glycoprotein in the embryonic and adult chick brain that induces growth cone collapse. Recombinant collapsin has potent collapsing activity against DRG growth cones but little activity against retinal growth cones, an activity profile opposite from that of the adrenal activity. Collapsing activities associated with oligodendrocytes (Bandtlow et al., 1990) or posterior somites (Davies et al., 1990) are also very effective against DRG growth cones and are therefore different from the adrenal activity. The adrenal derived activity must also be distinct from an avoidance cue associated with membranes from the posterior chick optic tectum (Stahl et al., 1990). This activity collapses temporal but not nasal retinal growth cones, while the adrenal derived activity collapses both temporal and nasal retinal growth cones equally well (data not shown). These considerations indicate that the adrenal activity is a novel collapsing factor.

The adrenal derived collapsing activity is likely to be a serine proteinase. Its activity is blocked by incubating adrenal extracts with the general serine hydrolase inhibitors NPGB, DFP, or PMSF, or with the active site directed irreversible inhibitor PPACK. It is formally possible that a serine proteinase activates a pro-collapsing activity in the adrenal extract. If the collapsing activity were generated in the adrenal extract, the late addition of PPACK to extracts preincubated in its absence should fail to block the collapsing activity. We have observed no such effect (data not shown). It is also unlikely that a pro-collapsing activity present in the extract is activated by serine proteinases produced by the retinal explant during the assay itself, since PPACK added to the extract and then removed by dialysis before the assay blocks collapse. The simplest explanation for our observations is that the collapsing activity in the adrenal extract is itself a serine protease.

The sensitivity of the adrenal derived collapsing activity to serine proteinase inhibitors further distinguishes it from other collapsing activities. No other growth cone collapsing activity that we are aware of is known to be similarly affected. The avoidance of posterior tectal membranes by temporal retinal growth cones is not blocked by serine proteinase inhibitors (Schlosshauer et al., 1990). Collapsin remains active after treatment with irreversible general serine proteinase inhibitors like NPGB, and it has no recognized sequence similarity to other serine proteinases (Luo et al., 1993).

We are naming the adrenal derived growth cone collapse inducing proteinase "erase" because it is a serine proteinase that causes growth cones to disappear. By naming this activity we do not mean to imply that erase is necessarily a previously uncharacterized serine proteinase. It is possible that erase's ability to induce the collapse of CNS growth cones is an interesting new activity of a previously characterized serine proteinase.

Although no other collapsing activity is known to be a serine proteinase, there is a serine proteinase, thrombin, that induces a dramatic retraction of neurites from both central and peripheral tissues grown in culture (Hawkins and Seeds, 1986; Gurwitz and Cunningham, 1988; Grand et al., 1989; Jalink and Moolenaar, 1992; data presented here). Like erase, thrombin is also very effectively inhibited by PPACK (Kettner and Shaw, 1981). Furthermore, prothrombin mRNA has been detected in DRGs of E15 rats using in situ hybridization (Dihanich et al., 1991). It is possible that erase is related to thrombin, however, several observations indicate that the two are not identical: (1) thrombin affects both central and peripheral growth cones while erase affects only central growth cones, (2) thrombin is inhibited by hirudin while erase is not, and (3) thrombin causes significantly 


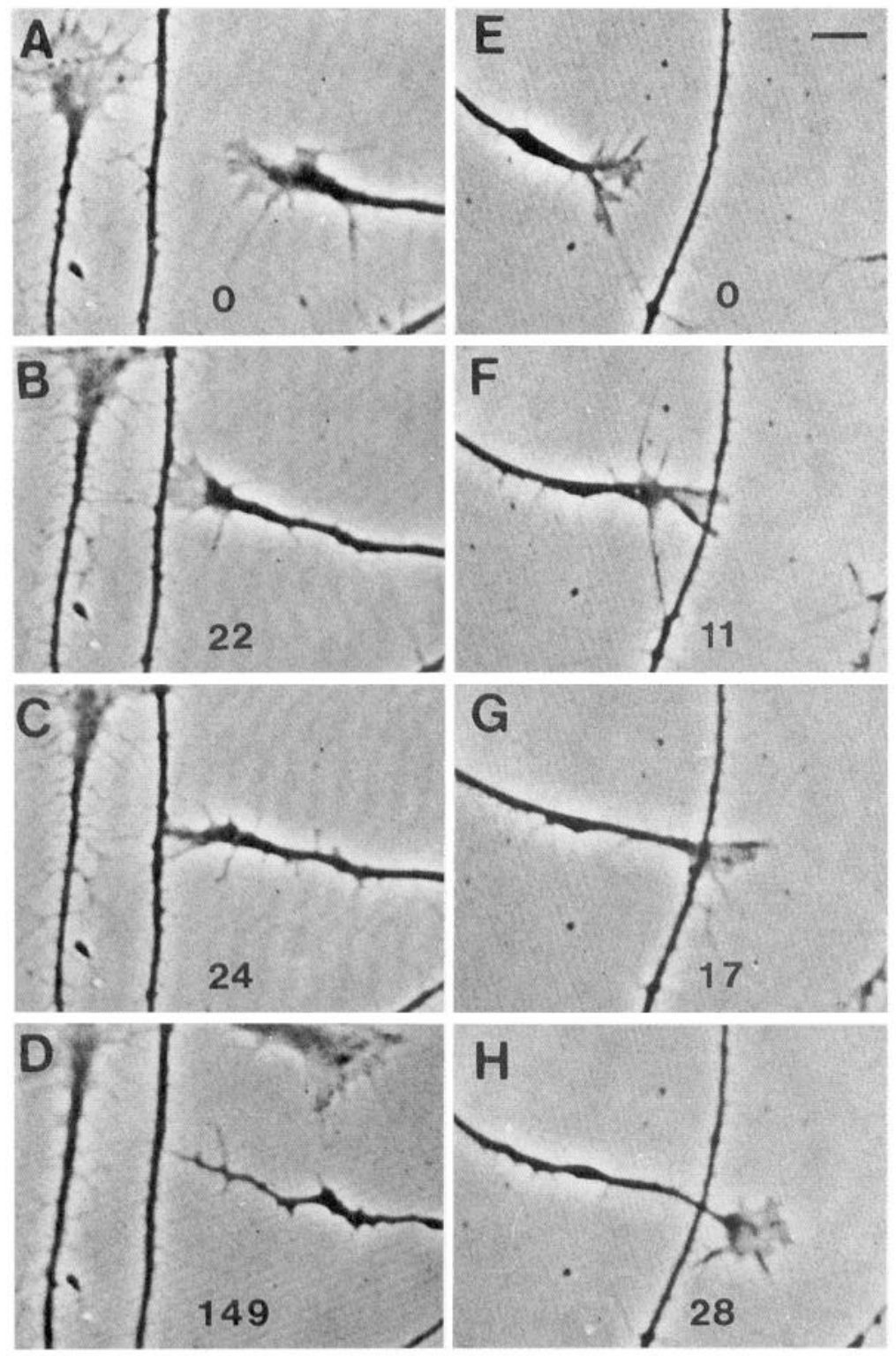

Figure 7. Temporal retinal ganglion cell growth cones contacting DRG neurites are less likely to collapse in the presence of PPACK. A comparison of the responses of temporal retinal growth cones to contact with DRG neurites in the absence $(A-D)$ or presence $(E-H)$ of $50 \mu \mathrm{M}$ PPACK. In the absence of PPACK, a retinal growth cone approaching a DRG neurite from the right has a spread and motile morphology when one of its filopodia first touches the DRG neurite $(A)$. After making contact with the neurite along most of its leading edge $(B)$, the growth cone collapses $(C)$, and remains collapsed for more than $2 \mathrm{hr}(D)$. In the presence of PPACK, a retinal growth cone approaching a DRG neurite from the left has a spread and motile morphology when one of its filopodia first touches the DRG neurite $(E)$, the lamellae remain active and cross the DRG neurite without collapsing $(F-H)$. Minutes are indicated at the bottom of each panel. Scale bar, $10 \mu \mathrm{m}$.

greater neurite retraction than erase when each is used at concentrations which cause only a portion of tested growth cones to respond. It is possible that some other known proteinase has properties more like those of erase, but our tests with Factor $\mathrm{Xa}$, tissue plasminogen activator, and urokinase have thus far failed to identify a likely match.

How might erase initiate growth cone collapse? One trivial possibility is that its enzymatic activity damages the adhesive substratum on which the growth cones extend or the receptors they use to adhere to the substratum. It is likely that the extension of both retinal and DRG growth cones on laminin is mediated by a $\beta_{1}$ containing integrin since both types of neurites detach from laminin when treated with the CSAT antibody. It is unlikely that proteolysis of a laminin substratum could specifically affect retinal growth cones without having a comparable effect on DRG growth cones, or that the effect could be reversible. Moreover, proteolysis of specific components of the substratum or the receptors used to recognize them are ruled out by the finding that erase collapses retinal but not DRG growth cones extending on two entirely different substrata, laminin and
G4, which are recognized by independent receptors (Lemmon et al., 1989; Kleinman et al., 1991; Kuhn et al., 1991; Reichardt and Tomaselli, 1991). It therefore seems likely that erase induces collapse by some other more direct effect on growth cones.

What other ways could a serine proteinase initiate growth cone collapse? The interaction of thrombin with its receptor provides an attractive model for the action of erase on growth cone collapse. The thrombin receptor is a member of the seven transmembrane receptor family. Thrombin is thought to first bind to its receptor and then cleave off a piece of the receptor's N-terminal end. Thrombin proteolysis of the receptor thereby unmasks a portion of the receptor that acts as a tethered ligand to activate the receptor. Peptides corresponding to this region of the receptor can mimic thrombin activation of platelets (Vu et al., 1991). Activation of the thrombin receptor in platelets causes an influx of $\mathrm{Ca}^{+2}$ and activation of pertussis sensitive $\mathrm{G}$ proteins (Purdon et al., 1984; Brass and Joseph, 1985; Brass et al., 1986). Activation of the thrombin receptor in neuroblastoma cells can be blocked by inhibitors of tryosine kinases and phosphatases (Jalink and Moolenaar, 1992). Both $\mathrm{Ca}^{+2}$ and pertussis sensitive 

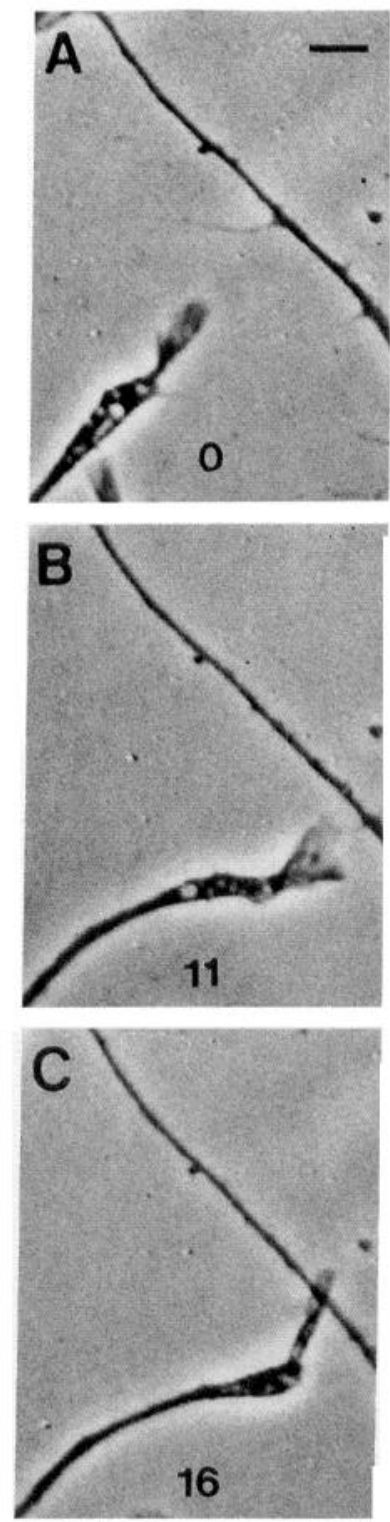

A temporal retinal ganglion cell growth cone in the presence of 50 $\mu \mathrm{M}$ PPACK is delayed in crossing a DRG neurite. Not all temporal growth cones cross DRG neurites without delay in the presence of $50 \mu \mathrm{M}$ PPACK. A retinal growth cone approaches a DRG neurite from the left $(A-D)$ and collapses on contact with the DRG neurite $(E, F)$. A new growth cone is assembled $(G)$, advances across the neurite $(H, I)$, retreats slightly while remaining motile $(J, K)$, and then advances across the neurite. The growth cone's lamellae in $J$ are out of the plane of focus and are indicated by arrowheads. Minutes are indicated at the bottom of each panel. Scale bar, $10 \mu \mathrm{m}$.

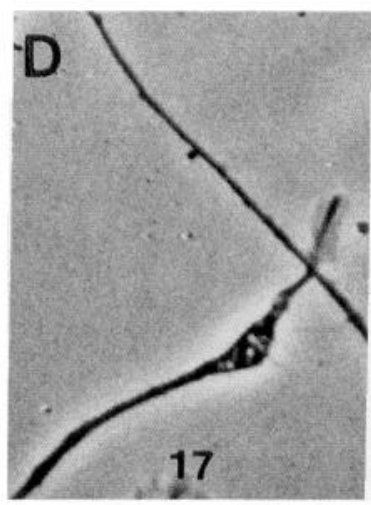

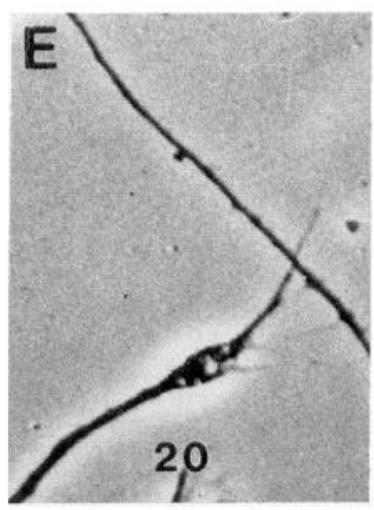
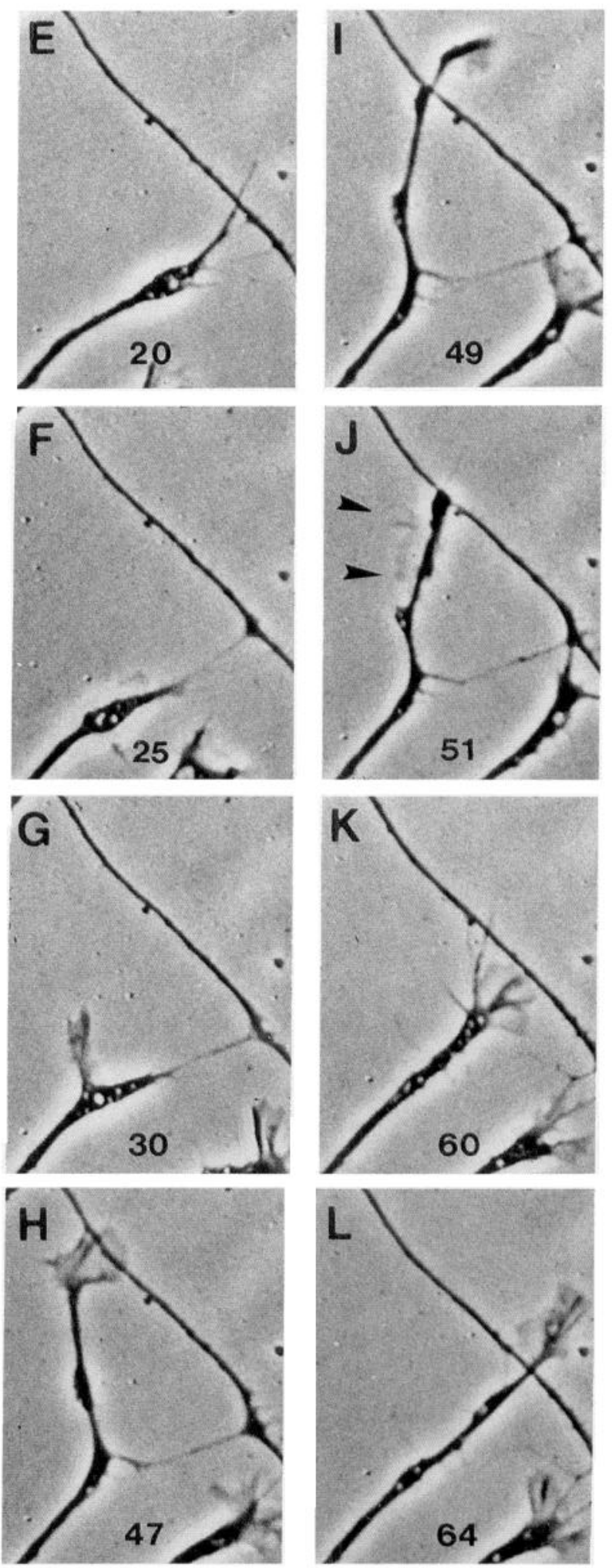

$\mathrm{G}$ proteins have been suggested to play a role in some forms of growth cone collapse (Bandtlow et al., 1993; Igarashi et al., 1993). Neurite retraction in neuroblastoma cells can be initiated by the same peptide fragment of the thrombin receptor that causes platelet activation, suggesting that thrombin causes neurite retraction through activation of its receptor (Jalink and Mool- enar, 1992; Suidan et al., 1992). A similar receptor mechanism may mediate erase's induction of growth cone collapse.

A proteinase could also initiate growth cone collapse without directly activating a receptor. Cleavage of another molecule on DRG axons could generate a locally diffusible collapsing molecule. An example of this kind of proteinase action is seen in 
A.

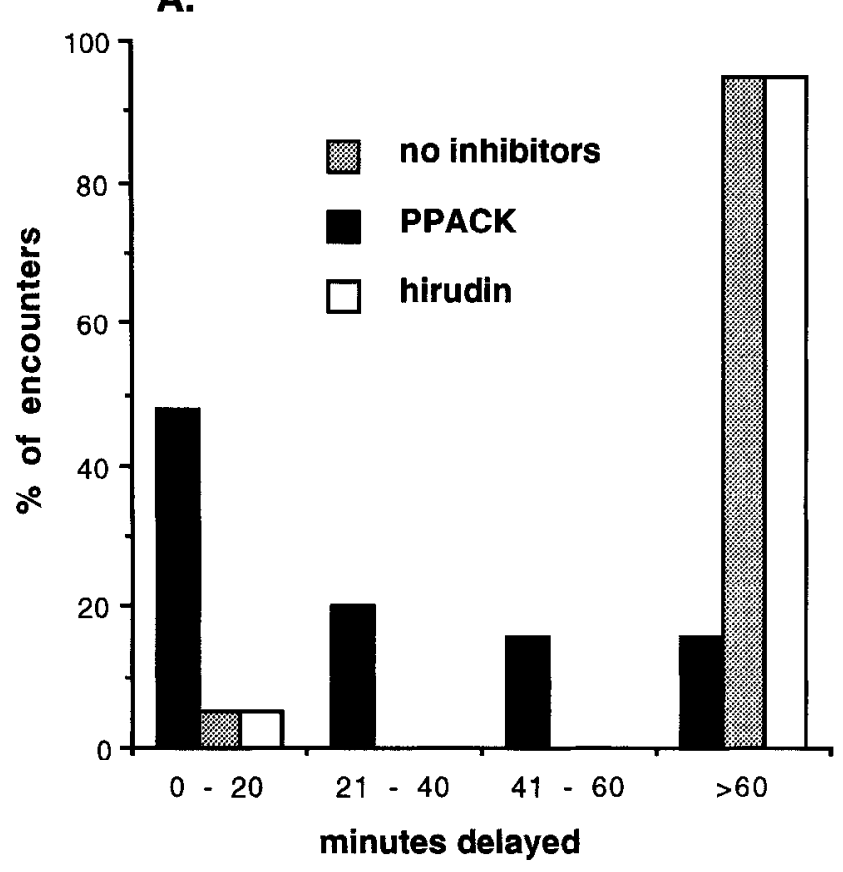

B.

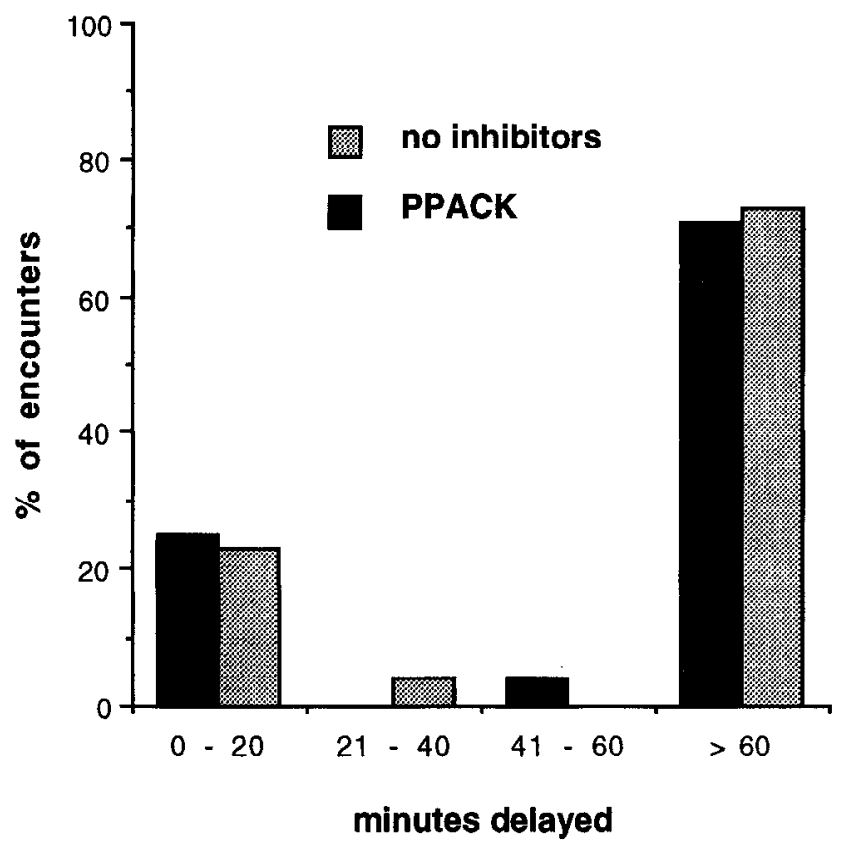

Figure 9. Temporal retinal ganglion cell growth cones cross DRG neurites more rapidly in the presence of $50 \mu \mathrm{M}$ PPACK. A, The crossover delays for encounters with DRG neurites are shortened in the presence of PPACK. The percentage of growth cones that were delayed by the indicated amount are indicated for all encounters in the absence of inhibitors (stippled bars) the presence of $50 \mu \mathrm{M}$ PPACK (solid bars), and the presence of $5 \mathrm{U} / \mathrm{m}$ hirudin (open bars). In the absence of inhibitors or the presence of hirudin, nearly all growth cones are delayed by $60 \mathrm{~min}$ or more. Delays are shifted to shorter values in the presence of PPACK. $B$, The presence of PPACK has no effect on crossover delays in encounters with nasal retinal neurites. The percentage of growth cones that were delayed by the indicated amount are indicated for all encounters in the absence of inhibitors (stippled bars) and the presence of $50 \mu \mathrm{M}$ PPACK (solid bars). The majority of growth cones in either condition are delayed by $60 \mathrm{~min}$ or more. PPACK does not affect the distribution of delay times. the generation of peptides chemotactic for neutrophils by neutrophil elastase from heparin cofactor II (Church et al., 1991). Along these lines the existance of diffusible chemorepulsive molecules have been reported (Fitzgerald et al., 1993; Pini, 1993). It is unlikely that erase generates a collapsing activity from some component of the assay medium since the assay works in medium containing serum but no bovine pituitary extract (BPE), BPE but no serum, and neither serum nor BPE (data not shown). It is unlikely that erase generates a collapsing activity from some component of the adrenal extract itself since the addition of PPACK to extract that has been pre-incubated at room temperature for $2 \mathrm{hr}$ in its absence is just as effective in blucking collapse activity as earlier additions without preincubation (our data, not shown).

The adrenal derived collapsing activity is a good candidate for the cue on peripheral axons that induces collapse of retinal ganglion cell growth cones. First, the adrenal activity affects retinal ganglion cell growth cones but not DRG or sympathetic growth cones, just like the peripheral axon activity. Second, the adrenal activity is largely neutralized by treatment with the irreversible and specific tri-peptide serine proteinase inhibitor PPACK, as is the collapse of retinal growth cones on contact with DRG axons. The blocking effect of PPACK on either the adrenal derived or the peripheral axon collapsing activities are not likely to be mediated by the inhibition of thrombin. Hirudin, a specific inhibitor of thrombin action is ineffective in blocking either activity.

PPACK is likely to neutralize the inhibitory cue on DRG axons that induces retinal collapse, and not to simply interfere in a more general way with the ability of retinal growth cones to respond to such cues. An avoidance cue on nasal retinal axons that is different from that on peripheral axons also induces the collapse of temporal growth cones (Raper and Grunewald, 1990). There is no difference between the responses of temporal growth cones to nasal neurites in the presence or absence of PPACK by any of the parameters measured. We conclude that PPACK does not directly affect the ability of temporal retinal growth cones to collapse, but specifically inhibits the ability of DRG neurites to induce collapse. We cannot rule out, however, the possibility that PPACK somehow affects an intracellular pathway that is specifically activated by the peripheral avoidance cue.

The simplest interpretation of our data that is consistent with the specificity with which erase induces collapse of retinal growth cones, and the ability of PPACK to block retinal collapse on contact with DRG neurites, is that a serine proteinase similar or identical to erase induces the collapse of retinal growth cones when they contact DRG neurites.

We do not know the physiological function of erase during normal development. However, because our studies implicate erase as a peripheral axon label that repulses a variety of central growth cones, it is possible that erase plays a repulsive guidance role when outgrowing axons of the PNS and CNS confront one another. One region in which such a confrontation occurs is in the dorsal spinal cord and lateral brainstem as sensory axons invade the CNS. One reasonable hypothesis is that erase associated with peripheral axons prevents the fasciculation of central growth cones onto sensory tracts. Biochemical and molecular studies of erase should ultimately provide the reagents necessary to test this hypothesis. 


\section{References}

Bandtlow CE, Zachleder T, Schwab ME (1990) Oligodendrocytes arrest neurite growth by contact inhibition. J Neurosci 10:3837-3848.

Bandtlow CE, Schmidt MF, Hassinger TD, Schwab ME, Kater SB (1993) Role of intracellular calcium in NI-35-evoked collapse of neuronal growth cones. Science 259:80-83.

Bonhoeffer F, Huf J (1985) Position dependent proterties of retinal axons and their growth cones. Nature 315:409-410.

Bottenstein JE, Skaper, Varon SS, Sato GH (1980) Selective survival of neurons from chick embryo sensory ganglionic dissociates utiliz-* ing serum-free supplemented medium. Exp Cell Res 125:183-190.

Bradford MM (1976) A rapid and sensitive method for the quantitation of microgram quantities of protein utilizing the principle of protein dye binding. Anal Biochem 72:248-254.

Brass I.F, Ioseph SK (1985) A role for inositol triphosphate in intracellular $\mathrm{Ca}^{2+}$ mobilization and granule secretion in platelets. $\mathbf{J}$ Biol Chem 260:15172-15179.

Brass LF, Lapasota M, Banga HS, Rittenhouse SE (1986) Regulation of the phosphoinositide hydrolysis pathway in thrombin-stimulated platelets by a pertussis toxin-sensitive guanine nucleotide-binding protein. J Biol Chem 261:16838-16847.

Church FC, Pratt CW, Hoffman M (1991) Leukocyte chemoattractant peptides from the serin heparin cofactor II. J Biol Chem 266:704709.

Cox EC, Muller B, Bonhoffer F (1990) Axonal guidance in the chick visual system: posterior tectal membranes induce collapse of growth cones from the temporal retina. Neuron 2:31-37.

Davies JA, Cook GMW, Stern CD, Keynes RJ (1990) Isolation from chick somites of a glycoprotein fraction that causes collapse of dorsal root ganglion growth cones. Neuron 4:11-20.

Dihanich M, Kaser M, Reinhard E, Cunningham D, Monard D (1991) Prothrombin mRN $\Lambda$ is expressed by cells of the nervous system. Neuron 6:575-581.

Fan J, Raper JA (1995) Localized collapsing cues can steer growth cones without inducing their full collapse. Neuron 14:263-274.

Fan J, Mansfield G, Redmond T, Gordon-Weeks PR, Raper J (1993) The organization of F-actin and microtubules in growth cones exposed to a brain-derived collapsing factor. J Cell Biol 121:867-878.

Fitzgerald M, Kwait GC, Middleton J, Pini A (1993) Ventral spinal cord inhibition of neurite outgrowth from embryonic rat dorsal root ganglia. Development 117:1377-1384.

Godement P, Salaün J, Mason CA (1990) Retinal axon pathfinding in the optic chiasm: divergence of crossed and uncrossed fibers. Neuron 5:173-186.

Grand RJA, Grabham PW, Gallimore MJ, Gallimore PH (1989) Modulation and morphological differentiation of human neuroepithelial cells by serine proteinases: independence from blood coagulation. EMBO J 8:2209-2215.

Gurwitz D, Cunningham DD (1988) Thrombin modulates and reverses neuroblastoma neurite outgrowth. Proc Natl Acad Sci USA 85:34403444.

Hawkins RL, Seeds NW (1986) Effects of proteases and their inhibitors on neurite outgrowth from neonatal mouse sensory ganglia in culture. Brain Res 398:63-70.

Igarashi M, Strittmatter SM, Vartanian T, Fishman MC (1993) Mediation by $\mathrm{G}$ proteins of signals that cause collapse of growth cones. Science 259:77-79.

Jalink K, Moolenaar WJ (1992) Thrombin receptor activation causes rapid neuronal rounding and neurite retraction independent of classic second messengers. J Cell Biol 118:111-119.

Kapfhammer JP, Raper JA (1987a) Collapse of growth cone structure with specific neurites in culture. J Neurosci 7:201-212.

Kapfhammer JP, Raper JA (1987b) Interactions between growth cones and neurites growing from different neural tissues in culture. J Neurosci 7:1595-1600.

Kettner C, Shaw E (1981) Inactivation of trypsin-like enzymes with peptides of arginine chloromethyl ketone. Methods Enzymol 80:826841.

Kleinman HK, Weeks BS, Cannon FB, Sweeney TM, Sephal GC, Clement B, Zain M, Olson MOJ, Jucker M, Burrous BA (1991) Identification of a $110-\mathrm{kDa}$ nonintegrin cell surface laminin-binding protein which recognizes an A chain neurite-promoting peptide. Arch Biochem Biophys 290:320-325.

Kuhn TB, Stoeckli ET, Condrau MA, Rathjen FG, Sonderegger P
(1991) Neurite outgrowth on immobilized axonin-1 is mediated by a heterophilic interaction with $\mathrm{L} 1(\mathrm{G} 4)$. J Cell Biol 115:1113-1126.

Lemmon V, Farr KL, Lagenaur C (1989) L1-mediated axon outgrowth occurs via a homophilic binding mechanism. Neuron 2:1597-1603.

Lottenberg R, Christensen U, Jackson CM, Coleman PL (1981) Assay of coagulation proteases using peptide chromogenic and fluorogenic substrates. Methods Enzymol 80:341-361.

Luo Y, Raible D, Raper JA (1993) Collapsin: A protein in brain that induces the collapse and paralysis of neuronal growth cones. Cell 75: $217-227$.

Neff NT, Lowrey C, Decker C, Tovar A, Damsky C, Buck C, Horowitz AF (1982) A monoclonal antibody detaches embryonic skeletal muscle from extracellular matrices. J Cell Biol 95:654-666.

Pini A (1993) Chemorepulsion of axons in the developing mammalian central nervous system. Science 264:95-98.

Pillman RN, Ivins JK, Buettner HM (1989) Neuronal plasminogen activators: cell suface binding sites and involvement in neurite outgrowth. J Neurosci 9:4269-4286.

Purdon AD, Daniel JL, Stewart GJ, Holmsen H (1984) Cytoplasmic free calcium concentration in porcine platelets: regulation by an intracellular non-mitochondrial calcium pump and increase after thrombin stimulation. Biochim Biophys Acta 800:178-187.

Raper JA, Grunewald EB (1990) Temporal retinal growth cones collapse on contact with nasal retinal axons. Exp Neurol 109:70-74.

Raper JA, Kapfhammer JP (1990) The enrichment of a neuronal growth cone collapsing activity from embryonic chick brain. Neuron 2:21-29.

Rathjen FG, Wolff JM, Frank R, Bonhoeffer F, Rutishauser U (1987) Membrane glycoproteins involved in neurite fasciculation. J Cell Biol 104:343-353.

Reichardt LF, Tomaselli KJ (1991) Extracellular matrix molecules and their receptors: functions in neural development. Annu Rev Neurosci 14:531-570.

Salvesen G, Nagase H (1989) Inhibition of proteolytic enzymes. In: Proteolytic enzymes: a practical approach (Beynon RJ, Bond $J$, eds), pp 83-104. Oxford: IRL.

Schechter I, Berger A (1967) On the size of the active site in proteases. I. Papain. Biochem Biophys Res Commun 27:157-162.

Schlosshauer B, Walter J, Bonhoeffer F (1990) Is guidance of chick retinal axons in vitro influenced by proteases? Neurosci Lett 113: 333-338.

Seeds NW, Verral S, Friedman G, Hayden S, Gadotte D, Haffke S, Christensen K, Gardner B, McGuire P, Krystosek A (1992) Plasminogen activators and plaminogen activator inhibitors in neural development. Ann NY Acad Sci 667:33-40.

Sretavan DW (1990) Specific routing of retinal ganglion cell axons at the mammalian optic chiasm during embryonic development. J Neurosci 10:1995-2007.

Sretavan DW, Reichardt LF (1993) Time lapse video analysis of retinal ganglion cell axon pathfinding at the mammalian optic chiasm: growth cone guidance using intrinsic chiasm cues. Neuron 10:761777.

Stahl B, Müller B, von Boxberg Y, Cox EC, Bonhoeffer F (1990) Biochemical characterization of a putative axonal guidance molecule of the chick visual system. Neuron 5:735-743.

Suidan HS, Stone SR, Hemmings BA, Monard D (1992) Thrombin causes neurite retraction in neuronal cells through activation of cell surface receptors. Neuron 8:363-375.

Tsao MC, Walthall BJ, Ham RG (1982) Clonal growth of normal human epidermal keratinocytes in a defined medium. J Cell Physiol 110:219-229.

Vu T-KH, Hung DT, Wheaton VI, Coughlin SR (1991) Molecular cloning of a functional thrombin receptor reveals a novel proteolytic mechanism of receptor activation. Cell 64:1057-1068.

Walter J, Kern-Veits R, Huf J, Stolze B, Bonhoeffer F (1987) Recognition of position-specific properties of tectal cell membranes by retinal axons in vitro. Development 101:685-696.

Wizenmann A, Thanos S, Boxberg Y, Bonhoffer F (1993) Differential reaction of crossing and non-crossing rat retinal axons on cell membrane preparations from the chiasm midline: an in vitro study. Development 117:725-735.

Zurn AD, Nick H, Monard D (1988) A glia-derived nexin promotes neurite outgrowth in cultured chick sympathetic neurons. Dev Neurosci 10:17 24 . 